III. SOBRE ECONOMÍA ECLESIÁSTICA 


\title{
ASPECTOS ECLESIÁSTICOS DEL MONASTERIO CISTERCIENSE DE LA VALLDIGNA EN LOS SIGLOS XVI Y XVII
}

POR

\author{
Eugenio Ciscar Pallarés
}

\section{Resumen}

Tras analizar diversos aspectos demográficos y sociologicos de los monjes de Valldigna en el siglo XVI y XVII, se atiende a su organizacion institucional y vida monástica, en general bastante "relajada", estudiando los intentos de reforma (de dudosa eficacia), para finalmente perfilar la problemática de las parroquias atendidas por religiosos conventuales (titularidad, dedicación, tierras, diezmos, escusado).

\section{Abstract}

Eclesiastical Features in the Monastery "De la Valldigna" in the XVIth $-X V I I^{\text {th }}$ Centuries.

The study analyces different general, demografic, and sociological, questions on the monks of the Monastery "De al Valldigna" during the XVI ${ }^{\text {th }}-\mathrm{XVII}^{\text {th }}$ centuries. Afterwards, it describes his Institutions and the monastical, in general terms, success. Finally, there are studied some questions about the different Parishes wich were serviced by people of the Convent (Titurality, Dedication, Lands, Tithes).

Larga y compleja es la vida del Císter desde que a finales del siglo XI Roberto y San Bernardo iniciaron su andadura hasta nuestros días. Por ello, den-

Sobre economia Eclesiástica Hispania Sacra 49 (1997) 
sa, frondosa y a veces polémica es su historiografia ${ }^{1}$. En el ámbito español, y de manera más concreta, aún se puede afirmar, a nuestro juicio, que es mayor nuestra información sobre el Císter de la Corona de Castilla (y su primeriza Congregación) que sobre el de la Corona de Aragón durante los siglos XVI y XVII. En ese sentido pretendemos aquí ofrecer algunos aspectos eclesiásticos o monásticos sobre la Valldigna, el monasterio más meridional de la Orden en la Corona de Aragón, situado en un valle abierto al Mediterráneo al sur de la actual provincia de Valencia, el más rico e influyente del Reino aludido durante la época de referencia ${ }^{2}$.

\section{I) DEMOGRAFÍA Y SOCIOLOGÍA DE LOS MONJES VALLDIGNENSES.}

El número de monjes del monasterio de la Valldigna varió con el tiempo y las circunstancias ,pero siempre mantuvo un nivel aceptable o incluso alto, lejos de las situaciones de penuria humana que presagiaban en otros conventos el peligro, cuando no la conveniencia de su cierre. Así, hacia 1535 se habla de cerca de sesenta religiosos, cantidad sin duda poco precisa y quizá algo exage-

I Con carácter meramente orientador, puede citarse:MAHN, J. B.,L'Ordre Cistercien et son Gouvernement, des origines au milieu du XII siecle (1098-1265),Paris, 1951; LEKAI, L., Los cistercienses. Ideales y Realidad,Barcelona, 1987; CocHERIL, M.,Efudes sur le Monachisme en Espagne et au Portugal, Lisbonne, I966; IDEM, Dictionnaire des Monasteres Cisterciens, Rocheforts (Belgique),1972-76, 2 vols; MARTIN, E.; Los Bernardos Espafioles. Historia de la Congregación de Castilla de la Orden del Cister,Palencia, 1953; MASOLIVER, A., Origen y primeros años (1616-1634) de la Congregación cisterciense de la Corona de Aragón.Stntesis historica y documentos, Abadia de Poblet, 1973. Sobre algunas abadias en concreto, entre otros: ALTISENT, A., Historia de Poblet, Barcelona 1974; BUENo DOMINGUEZ, M* L., El Monasterio de Santa Maria de Moreruela (II43. 1300). Valladolid,1975; ALFONSO ANTON, I, La colonizacion cisterciense en la Mesefa del Duero.EI dominio de Moreruela (siglos XI-XIV), Zamora, 1986; BARBASTRO GIL, L., El seftorio del monasterio de Rueda (1202-1835), Zaragoza, 1993; GARCIA MARTTN, P.El monasterio de San Benito el Real de Sahagún en la Epoca Moderna, Salamanca, 1985; LOPEZ LANDA, J. M., Abadías Cistercienses de la Antigua Congregación de Aragón y Navarra, Calatayud, 1949; GALJNDO, M.,El Real Monasterio de Santa María de Benifazá, Tortosa, 1916; Lladonosa I Pujol, J.,El Real Monasterio de Santa Maria de Vallbona, Lleida, 1957; MORA CAÑADA, A.,Monjes y campesinos. El señorio de Valldigna en los siglos XVH y XVII, Alicante, 1986.

2 Si bien la mayoría de la documentación conservada en el Archivo del Reino de Valencia(ARV) y estudiada cs de índole económica o relativa a la justicia señorial,no faltan aspectos complementarios de interes en otros campos, completados con noticias de otros archivos. Su bibliografia es muy amplia, pero destacamos por su mayor atención a aspectos monásticos: TOLEDO GiRAU, J., "El monasterio de Valldigna. Contribución al estudio de su historia durante el gobierno de sus abades perpetuos", en Anales del Centro de Cultura Valenciana, Primera época,IX (1936) y Segunda época,I,III,IV y V (1940-1944);"El monasterio de Valldigna y sus abades comendatarios", en Boletin de la Sociedad Castellonense de Culura, XXII (1946); CABANES PECOURT, M'. D., Los monasterios valencianos. Su economía en el siglo XV, Valencia, 1974, 2 vols.

Sobre economía Eclesiástica

Hispania Sacra 49 (1997) 
rada $^{3}$. Hacia 1563 se afirma que en los años treinta había "pus de trenta frares de mija y en altres frares, religiosos y criats en suma y numero de mes de sexanta persones" y para los años cincuenta, entre "monjes, frares e moços pus de cinquanta persones"4. Bien informado y mas ajustado suele ser en general el cronista Martín de Viciana, quien hacia 1560 alude a 36 monjes y 15 frailes ${ }^{5}$. Poco después, en 1572-73,se citan 47 religiosos y los novicios ${ }^{6}$. Más de treinta años después, en 1607 , son 56 monjes y 15 frailes legos, la mayor cifra conocida, a lo que había que añadir unos 36 criados $^{7}$. Es indudable que el número de religiosos había ido creciendo a lo largo del siglo XVI hasta alcanzar el de 71 en 1607, cifra que quizá era excesiva y que coincide con un momento de gran tensión y división en la comunidad cisterciense.

Las dificultades generales del Seiscientos, más las propias del convento (impacto de la expulsión de los moriscos), hicieron descender el número de religiosos. Hacia 1618 y en un documento poco preciso se alude a treinta monjes y diez frailes, lo que parece un descenso excesivamente brusco ${ }^{8}$. En cambio, se evaluan de forma general en el período 1681-1685 en 55,los cuales tienen a su servicio más de 20 criados$^{9}$. Cifra media que no se contradice con el número de monjes y frailes o hermanos conversos que quedan registrados en los inventarios o nóminas conventuales efectuadas con ocasión de la elección de algunos abades ${ }^{10}$ (Cuadro I), relación que tiene caracter general o total y es muy superior a la de los que realmente votan ${ }^{11}$.De todos estos datos se des-

${ }^{3}$ AHN (Archivo Historico Nacional), Osuna,leg. 799, $\mathrm{n}^{\circ} 67$.

${ }^{4}$ ARV,Real Audiencia, procesos, $2^{n}, S, n^{\circ} 86$, proceso sobre los diezmos de la granja de Benivayre.

5 VICIANA, M. de, Cronica de la Inclita y Coronada Ciudad de Valencia, vol III, p.88 (Edición facsimil, Dpto. $H^{\circ}$ Moderna, Valencia, 1971).

6 ARV , Cl (Clero), libro 1.696, f. 229.

7 ACA (Archivo de la Corona de Aragón), CA (Consejo de Aragón), leg. 866, n. ${ }^{\circ} 12-1$, doc. de 24-VIII-1607.

- Se trata de una estadística general de los monasterios de la Corona de Aragón y de sus religiosos en el período de la constitución de su Congregación. Estos se cuantifican en 300 monjes y 78 frailes legos. El principal con gran diferencia es Poblet y sus centros dependientes, con 100 monjes más 40 frailes legos, seguido de Santes Creus con 40 (10 legos),Veruela con 34 (seis legos) y Valldigna con 30 más los 10 frailes legos ya citados(MASOLIVER, A.,Origen y primeros.,p. 385-388).

9 ARV, Cl, caja (c.) 2075-76, relación de rentas de 1681 a 1685 . Poco antes, refiriendose al periodo 1644 a 1665 , R. Trobado afirmara que de media habia unos cuarenta monjes y de diez a doce legos en el monasterio (Defensa a la Magestad Católica..., Madrid, 1667, fol. 53), lo que coincide con las estadisticas del cuadro I.

10 ARV, Cl, libro 3.953 ,fols. 85, 86, 90, 108, 125, 142, 163, 166, 170, 175. En 1656 se registran 44 monjes, 7 hermanos conversos y 4 novicios. De los 14 conversas de 1700, dos son frailes "zullos", asi como dos monjes de los 43 de 1716 .

11 Así, no participan en la elección los monjes ausentes, los privados de voz activa por diversas causas y los frailes legos o conversos. Se han conservado algunas actas de los participantes en este acto, siempre "monachis profesis", con los siguientes números de intervinientes: 1560, 26; 1585,34; 1588,31; 
prende que desde 1649 el número de religiosos oscila en torno a cincuenta, con una tendencia clara a aumentar desde 1680 para alcanzar los sesenta o sesenta y dos a fines de siglo. De ellos, de un 15 a un $20 \%$ son conversos o legos.

\section{CUADRO I}

NUMERO DE RELIGIOSOS SEGUN LOS INVENTARIOS MONACALES

\begin{tabular}{|c|c|c|c|}
\hline AÑOS & MONJES & HERMANOS CONVERSOS & TOTAL \\
\hline 1649 & 44 & 9 & 53 \\
1652 & 42 & 7 & 49 \\
1656 & 44 & 11 & 55 \\
1660 & 40 & 7 & 47 \\
1668 & 38 & 10 & 48 \\
1672 & 41 & 8 & 49 \\
1680 & 42 & 12 & 54 \\
1692 & 46 & 10 & 56 \\
1697 & 46 & 10 & 56 \\
1700 & 47 & 14 & 61 \\
1704 & 48 & 14 & 62 \\
1716 & 43 & 9 & 52 \\
\hline
\end{tabular}

(ARV,Cl, libro 3.953)

No conocemos el origen geográfico de los religiosos durante el siglo XVI. La mayor información disponible de los abades nos permite algun avance meramente indicativo. Así, D. José Garrigues era de Carcaixent,D. Rafael Lluqui de Alzira, D. Juan Costeja de Luchent y D. Pedro Lopez de Triana (Sevilla). A partir de 1608, cuatro Abades proceden de Carcaixent (J. Talens, P. Tudo, V. Lloret y J. Espí), cuatro de Alzira (Nicolas y Francisco Talavera, F. García y F. Gari), dos de Valencia (F. Cruanes y G. Castillo), más uno de Onteniente (J. de la Tonda), Xátiva (R. Sanz de la Llosa), Canals (P. Saurina),Gandía (J. Caldero), Alicante (J. Serra), Pego (J. Torres) y Altura (J. Salvá) ${ }^{12}$.

1591,$30 ; 1604,36 ; 1607,45 ; 1611,48 ; 1640,28 ; 1676,29 ; 1668,28 ; 1676,29 ; 1697,35$ (ARV, Cl, c. 2.075.2076 y 2077). Observese como el máximo número de votantes se alcanza en 1607 y 1611 , para luego ir decayendo a lo largo del siglo y solo en 1697 parece detectarse una ligera recuperación.

12 Vid, lista de abades y algunas referencias biograficas en GASCON PELEGRI, V., Historia de Tavernes de Valldigna,(Valencia, 1.956, con una edición posteior de 1981) y una Cronica de Valldigna, manuscrita conservada en ARV,Cl, leg. 846. A estos datos habría que añadir el del abad D. Rafael Trobado, nacido en Valencia(ARV,Cl, c. 2.144-45, limpieza de sangre de 1621).

Sobre economía Eclesiástica

Hispania Sacra 49 (1997) 
Los expedientes de limpieza de sangre, linaje y costumbres de los novicios que solicitaban el hábito del Císter posibilitan una aproximación más fiable , al menos para el siglo XVII. Los 94 encontrados ${ }^{13}$ se distribuyen de la siguiente manera:

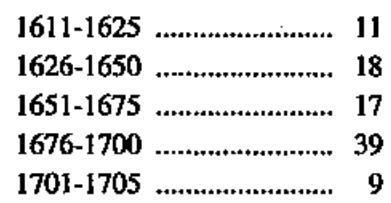

El Cuadro II pone de relieve que 50 novicios (53'1\%) proceden de cuatro ciudades pequeñas en un radio de 20-25 $\mathrm{Km}$. alrededor del monasterio: Gandía, Carcaixent, Alzira y Xátiva ${ }^{14}$.Otros $21\left(22^{\prime} 3 \%\right)$ tienen su origen en localidades, preferentemente pequeñas, en un radio de $50 \mathrm{Km}^{15}$. A la ciudad de Valencia corresponden 13 novicios (13'8\%), a lo que se suman otros casos aislados de otras localidades lejanas ${ }^{16}$ o la excepción de la regla: los oriundos de otros reinos distintos del de Valencia ${ }^{17}$.Solo dos aspirantes proceden de los pueblos contiguos y dependientes jurisdiccionalmente del monasterio: Tavernes y Simat (2'1\%).

La primera conclusión es evidente:los religiosos se reclutan preferentemente de las zonas próximas al monasterio, de tal manera que 71 novicios $\left(75^{\prime} 5 \%\right)$ han nacido en localidades a menos de $50 \mathrm{Km}$. . Completa el cuadro la ciudad de Valencia ( a poco más de esa distancia), de donde surgen algunas vocaciones, no obstante la abundancia de conventos y ordenes en la misma.

El $85 \%$ de los novicios proceden de áreas rurales, de las que solo podemos excluir los de Valencia y un caso conocido de Alicante. Pero tal afirmación debe ser matizada. A los 50 de Gandía, Carcaixent, Alzira y Xátiva podemos añadir otros más alejados aunque dentro del área de $50 \mathrm{Km}$.(Onteniente, Oliva,Denia, Cocentaina), con lo que son 58 los novicios $\left(61^{\prime} 7 \%\right)$ que de hecho han nacido en localidades bastante pobladas, con una estructura social más

${ }^{13} \mathrm{ARV}, \mathrm{Cl}$, leg. 737 (cajas 1.919 bis y 1920), leg. 739 (cajas 1924 y 1925), leg. 786 (cajas 2.050 y 2.051-52) y leg. 820 (cajas 2143 y 2144-45).

14 De Gandía son 16, 14 de Carcaixent,11 de Alzira y 9 de Xátiva.

15 De Onteniente cuatro,dos de Luchent y de Oliva y uno de Enguera,Tavernes de Valldigna, Simat,Murla, Denia, Beniganim,Xavea, Quatretonda, Albalat (de la Ribera), Cocentaina, Bellreguat, Montesa y Canals.

${ }^{16}$ Es el caso de Meliana, Traiguera,Chelva, Alicante,Ayora y Novelda.

17 Dos del Reino de Aragón (Muniessa y Alforque) y dos de Navarra (Miranda y Benivarre). 
compleja, que prestan ciertos servicios a su comarca y con alguna actividad artesanal, núcleos que podemos denominar como "pequeñas ciudades".

CUADRo II

ORIGEN GEOGRAFICO DE LOS NOVICIOS (1611-1705)

\begin{tabular}{|l|c|c|}
\hline ORIGEN & N. ${ }^{a}$ DE NOVICIOS & $\%$ \\
\hline $\begin{array}{l}\text { Ciudades medias próximas (Gandia, Al- } \\
\text { zira, Carcaixent Xátiva) }\end{array}$ & 50 & $\left(53^{\prime} 1\right)$ \\
\hline $\begin{array}{l}\text { Resto de pueblos en un } \\
\text { radio de 50 Km }\end{array}$ & 21 & $\left(22^{\prime} 3\right)$ \\
\hline Ciudad de Valencia & 13 & $\left(13^{\prime} 8\right)$ \\
\hline Otros (R' de Valencia) & 6 & $\left(6^{\prime} 3\right)$ \\
\hline Otros reinos & 4 & $\left(4^{\prime} 2\right)$ \\
\hline ToTAL & 94 & \\
\hline
\end{tabular}

Es mucha menor la información sobre el origen social de los aspirantes a monjes en los expedientes. Priman aquí las referencias a la pureza de sangre de la familia y buenas costumbres (célibes, sin deudas, sin haber entrado en otra "religión"...) que a la situación económica, profesional, etc..Los 27 casos conocidos se dividen de la siguiente manera: en nueve ocasiones, los padres ( y a veces el novicio) tienen el tratamiento de "Don"; ejercen o han desempeñado cargos de relevancia social y política, como D. Bruno Salcedo y Vives, oidor de la Real Audiencia, D. Antonio Perellós, "Governador" de Denia, o D. Domingo Trobado, Doctor "en Drets";el padre de D. Diego Bellvis (Xátiva) era señor de Benisuera y el de D. Jaime de la Tonda, "cavallero principal" de Onteniente. Es interesante observar que seis de los nueve casos corresponden a habitantes de la ciudad de Valencia. El relieve de los ascendientes del novicio llama la atención a los testigos, quienes no dejan de comunicarlo, por lo que cabe pensar que no hubiese ningun ejemplo más de miembros de la pequeña nobleza entre los 94 expedientes.

En dos casos se trata de profesiones paternas que exigen ciertos estudios, como notario y doctor en Medicina; en cinco, diversos oficios (albañil, cirujano, tintorero, sastre y "factor"); en seis, labradores, y, finalmente, de cinco la información es vaga pero interesante, pues se nos dice que los padres del novicio han sido Jurado Mayor y Justicia, o familiares del Santo Oficio o que son de las familias "antiguas" de la localidad.Si tenemos en cuenta que con alguna

Sobre economía Eclesíastica Hispania Sacra 49 (1997) 
frecuencia se alude a los novicios como "studiant", actividad que solo podían desempeñar los jóvenes cuyos padres tuviesen cierto desahogo económico y en algún núcleo de cierto volumen; si al menos 58 novicios proceden de pequeñas ciudades ${ }^{18}$ del área rural próxima al convento, además de los datos familiares citados, creemos que con prudencia se puede concluir que, además de una décima parte aproximadamente de novicios procedentes de la pequeña nobleza (9 entre 94 aspirantes), la gran mayoría venían de familias de los sectores medios y algo acomodados de pequeñas ciudades de ámbito nural (labradores, profesionales, artesanos...), ,con cierto relieve o importancia en sus localidades y con medios para poder dar alguna formación a un hijo que le permitiese ser admitido en el convento. Todo ello sin perjuicio de ejemplos de origen más modesto, que por otro lado no se han podido documentar.

Si comparamos la relación de religiosos que intervienen en la elección de Abad de un año determinado y en la siguiente elección cuatro años más tarde durante el siglo XVII' ${ }^{19}$, observamos (Cuadro III) una gran permanencia de los mismos en el monasterio, y en consecuencia una gran estabilidad de la comunidad.Los porcentajes obtenidos superan siempre el $80 \%$ y en algun caso se acerca al $100 \%$ (1656 respecto de 1652). A veces incluso conocemos que la causa de que un religioso no aparezca en la nómima es su fallecimiento: así 3 de las 9 ausencias en 1652 y 7 de las 10 en 1656. Por tanto, un buen número de las ausencias se debía a razones de tipo natural, que refuerzan aún más la impresión de continuidad y estabilidad esencial de la población conventiual.

\section{CuADRo III}

PERMANENCIA DE LOS RELIGIOSOS EN EL MONASTERIO

\begin{tabular}{|c|c|c|c|c|}
\hline ELECCIÓN & N. $^{0}$ DE RELIGIOSOS & ELECCIÓN & PERMANENCEN & $\%$ \\
\hline 1649 & 53 & 1652 & 44 & $83^{\prime} 0$ \\
1652 & 49 & 1656 & 48 & 979 \\
1656 & 55 & 1660 & 45 & $81^{\prime} 8$ \\
1668 & 48 & 1672 & 42 & 875 \\
1697 & 56 & 1700 & 52 & $92 ' 8$ \\
1700 & 61 & 1704 & 54 & $88 ' 5$ \\
\hline
\end{tabular}

(ARV, Cl, libro 3.953)

\footnotetext{
18 Son los casos citados en nota 9, más los de Onteniente, Cocentaina, Denia y Oliva.
}

19 Vid. nota 6. 
La introducción del sistema electivo de los abades entre los miembros de la comunidad a partir de 1530 , primero por períodos trienales y desde 1617 cuatrienales, permite observar aquellos casos en que se produjeron varias reelecciones (aunque no inmediatas), lo que nomalmente nos indica el poder e influencia de algunos religiosos sobre el resto de su comunidad. Así, en el período trienal hemos de citar a D. Gaspar Bellver (1530-36), D. José Garrigues (1550-53;1560-63; 1579-82;1588-91), D. Juan Fano (1553-56;1566-69;157879), D. Jaime Bellvis (1556-60; 1569-72; 1575-78),D. Francisco Gil (158588;1591-94), D. Bartolomé Serrano (1598-1601;1604), D. Juan Costeja (160104;1607-08).Menos son los casos entre los abades cuatrienales: D. Jaime ToITes (1620-24; 1628-31), D. Nicolás Talavera y Castellet (1624-28; 1631-32; 1636-40), D. Rafael Trobado (1644-48; 1652-56; 1660-64) y D. Vicente Lloret (1680-84;1692-97).El origen noble de los candidatos no fué determinante, pues solo encontramos dos casos en el siglo XVI (D. Juan Fenollet y D. Jaime Bellvis) y otros dos en el XVII'(D. Rafael Trobado y D. Jaime de la Tonda).

Se alcanza la dignidad de abad a una edad avanzada y tras muchos años de hábito. Así, D. Francisco Cruañes es elegido en 1649 a los 60 años de edad y 43 de hábito; en 1656, D. Pedro Tudo,a los 38 y 21; en 1668, D. Francisco Monreal, 56 y 30 ;en 1672, D. Francisco Gari, 46 y 30 ;en 1680, D. Vicente Lloret, 41 y 23 ; en 1697, D. José Castillo, 43 y 26 respectivamente ${ }^{20}$. De otro modo, el expediente de limpieza de sangre de $\mathrm{D}$. Rafael Trobado es de 1621 y fué elegido por primera vez en 1644; D. Jaime de la Tonda, 1636 y 1665; D. Jerónimo Espí,1657 y 1684, respectivamente. Cifras indicativas también de que muchos "estudiantes" ingresaban en el convento cuando apenas eran adolescentes.

Si bien el objetivo esencial de una comunidad monástica es el perfeccionamiento espiritual, la formación cultural nunca debe faltar. Los escasos datos de que disponemos hacen pensar que no fué aquella especialmente brillante en la Valldigna, sino más bien bastante deficitaria a juicio de algunas informaciones. Así, ya en el informe de la visita del abad de Claraval en 1532 se pone de relieve la ignorancia de muchos jovenes, ordenandose que un maestro de escuela cuide de su formación, al menos en cuestiones gramaticales, y que más adelante nadie sea destinado a recibir las sagradas órdenes y máxime al sacerdocio si no sabe hablar y entender el latín suficientemente ${ }^{21}$. En la visita que , a instancia del arzobispo de Valencia Juan de Ribera, se efectúa en 1570 a las parroquias del valle y a los frailes que las regentaban, se puso de manifiesto que estos, incluído el abad D. Jaime Bellvis, no sabían "construir" en latín, así

20 Vid. nota 6.

21 AHN,Clero, pergaminos, carpeta 3.395, pergamino 11. Publicado y traducido en BRoNSEVAL, C.,Viaje por la Valencia del siglo XVI, Valencia 1993,p. 128-136.

Sobre economía Eclesíastica

Hispania Sacra 49 (1997) 
como que algunos tenían profunda ignorancia en conceptos esenciales de la doctrina cristiana(vg., los sacramentos) ${ }^{22}$.De los pártocos se dirá en 1595 que no son "graduados en letras"23 y de los religiosos en general en 1591 que "pocos saben letras"24. Del conjunto de los frailes en el siglo XVI solo conocemos que fueron doctores en Teología D. Gaspar Bellver, D. Cosme Amer y D. José Garrigues, los tres abades del convento.

Con la formación de la Congregación Cisterciense de Aragón, se creó un colegio en Huesca para estudios de la Cogregación, del que fueron rectores los monjes valldignenses D. Jerónimo Espí, D. Vicente Lloret y D. Rafael Trobado, que posteriormente alcanzaron la dignidad abacial. Este áltimo fué quizá el religioso más brillante del siglo XVII, pues a su origen acomodado y culto25 unía ser maestro en Teología y doctor por la Universidad de Valencia, donde ejerció como catedrático, así como enseñó Artes en Xátiva; fue en dos ocasiones Vicario General de la Congregación Cisterciense de Aragón, abad del monasterio en tres períodos y apareció varias veces en las ternas para el cargo de obispo de Segorbe y Orihuela ${ }^{26}$. Otros ilustres monjes que destacaron por su cultura en el Seiscientos fueron el setabense Pedro Galiana, el gandiense Francisco Sebastiá y el abad José Castillo ${ }^{27}$. No obstante, los Estatutos de la Congregación de 1626 apenas señalaban tiempo para el estudio en la distribución horaria de los monjes ${ }^{28}$. Todavía en la visita de $1698^{29}$ se ordenará que no se descuidase el examen de "literatura" de los jovenes en el momento de su ingreso, el informe de calidad y costumbres con ocasión de su "vestición", así como que se les asignase un padre "de mucho ejemplo" para enseñarles.

\section{II) ORGANIZACION Y VIDA MONASTICA}

Dentro del común denominador de observar la Regla benedictina, con la interpretación que le daba Citeaux, cada monasterio gozaba de una amplia

22 ARV,Cl, caja 2.013-14, procesos a instancias del fiscal eclesiástico contra los rectores de la Iglesias del Valle, año 1570.

23 AHN, Consejos, libro 2397, fol. 249-250.

24 ACA,CA, leg. 651, $\pi^{\circ} 76,23$ de Junio de 1591.

25 Su expediente de limpieza de sangre se conserva en ARV,Cl, c. 2.144-45. Rafael Trobado y Figuerola era natural de Valencia,hijo de Domingo Trobado, "Doctor en drets", y de D" Francisca Figuerola, así como nieto de Gabriel Trobado, familiar del santo Oficio.

26 Vid. nota 12.También, Trobado, R., Defensa a la Magestad Catolica..., fol. $40 \mathrm{v}^{\circ} \mathrm{y}$ ss.

27 TOLeDO GIRAU, J., El Archivo-Biblioteca del Real Monasterio de Valldigna, Castellón de la Plana, 1944, p. 35- 37.

${ }^{28}$ MASOLIVER, A.,op. cit., p. 141.

29 ARV,Cl, c. 1954. 
autonomía. En la peculiar estructura organizativa de la Orden, prefijada en su "Charta Caritatis", la Valldigna como abadía era un organismo autónomo, "hija" y fundada por monjes del monasterio de Santes Creus en 1298, encargado de "visitarla" y por tanto de velar por su adecuado funcionamiento, misión que en circunstancias excepcionales podía asumir el abad del Císter, un "primus inter pares" respecto de los demás abades. Este sistema descentralizado tenía su nexo de relación en el Capítulo General de todos ellos, que debía celebrarse cada año y cuya asistencia era obligatoria. La expansión espacial del Císter y la complejidad progresiva de los asuntos a tratar condujo a la remisión de algunos de ellos a comisiones (Definitorio) asi como al absentismo generalizado.

La relajación de muchas comunidades religiosas, patente ya en el siglo XIV, y la diversidad y dispersión de ellas impulsará un movimiento complejo tendente a crear agrupaciones o "provincias" de monasterios, con una estructura institucional distinta de la descrita, llamadas Congregaciones,que fueron vistas con recelo y resistencia por los centros fundacionales en Francia o por los más adictos al sistema tradicional. La primera de ellas fue la de Castilla, promovida por fray Martin Vargas (1425), que solo quedará consolidada en el siglo XVI y totalmente independizada del Císter,como la de Portugal(1567), entre otras Congregaciones (Toscana y Lombardía, Calabria y Lucania, Nápoles, Alemania...), cada una con su organización propia y diversa. Este impulso será favorecido en el Quinientos por los monarcas españoles, en particular por Felipe II, como un medio idóneo para proceder a la reforma monástica acorde con los nuevos tiempos de renovación religiosa, en particular en el caso de la Corona de Aragón. Se intentó aquí crear una Congregación similar al menos a la de Castilla, obteniendo la preceptiva autorización del papa, pero tendrá que superar la resistencia del poderoso Abad del Císter, del Rey de Francia y de algunos monasterios remisos al proceso. Finalmente, el Breve de 19 de abril de 1616 de Paulo $\mathrm{V}$ autorizó su erección, a la que posteriormente se uniran los monasterios navarros (Bula de Urbano VIII de 10 de mayo de 1634).

La Congregación de la Corona de Aragón permaneció siempre unida al Císter, aunque con nexos de unión bastante vagos. En sus Estatutos, rompiendo con la vinculación a la abadía-madre, se implanta un abadiato cuadrienal irreelegible inmediatamente (rompiendo así con la tradición de abades perpetuos, cuando no comendatarios), aunque a propuesta de una terna formulada externamente por el Vicario General y los Definidores; se perfila un gobierno de la Congregación compuesto por un Vicario General, que preside el Capítulo Provincial, elegido rotativamente por los distintos reinos de la Corona de Aragón y sujeto al Abad del Císter; tres definidores, uno por cada reino (Aragón, Catalunia-Mallorca y Valencia), dos visitadores y un secretario, cargos todos

Sobre economía Eclesiástica Hispania Sacra 49 (1997) 
ellos cuatrienales ${ }^{30}$. Una célula de este proceso es la Valldigna, a la que nos ceniremos esencialmente.

Desde su fundación el monasterio estuvo regido por abades perpetuos elegidos entre y por los religiosos de la comunidad, tal como era habitual en otras casas de la orden. No obstante, en la primera mitad del siglo XV empezaron a surgir incidentes que presagiaban la intervención dirigista del papa o del monarca. Así, Benedicto XIII nombró en 1415 abad de Valldigna a quien lo era de la Real de Mallorca; en 1424-27 la comunidad se divide en la obediencia a dos abades simultaneos, uno miembro de la misma y otro, fray Berenguer Vich, de prestigio e influencia en la Corte, que acabó incorporandose al convento y convirtiendose en ánico abad; éste último será cesado por el rey D. Alfonso $V$ por la deficiente gestion de la hacienda valldignense en 1442; otra vez en 1448 hubo que superar el nombramiento papal de un foráneo para el cargo y los religiosos eligieron a Fray Pedro Baldó.

Cuando en 1460 éste fué propuesto como obispo de Segorbe por el rey Juan II, el patronato del abadiato acabó en manos de los monarcas, quienes con la benevolencia del papado fueron proponiendo para el cargo a personajes de su familia o de su entorno cortesano, y en cualquier caso totalmente ajenos a la comunidad de religiosos del monasterio. Varios de ellos fueron miembros de la influyente familia Borja, como D. Rodrigo de Borja, cardenal y luego papa Alejandro VI; D. Cesar de Borja , cardenal y arzobispo de Valencia; D. Pedro Luis de Borja, o D. Alonso de Aragón (1512-18), hijo del Rey Fernando II, que fué a su vez arzobispo de Zaragoza y Valencia, patriarca de Jerusalem y abad de Rueda. En estas circunstancias, el absentismo de los titulares de la Valldigna fue general, nombraron prior para regir la comunidad y administradores o procuradores, atentos ante todo al cobro de las rentas. Tal situación disgustaba evidentemente a los monjes residentes tanto en el plano espiritual como temporal y desde 1499-1500, al renunciar D. Cesar Borja a la mitra valldignense, iniciaron diversas gestiones ante el monarca para obtener su renuncia al patronato a cambio de una compensación económica y el otorgamiento a los religiosos del derecho a elegir entre ellos abad por un periodo trienal, a fin de que el peligro del mal gobierno del mismo no se perpetuase hasta su muerte. Hasta en tres ocasiones eligieron abad trienal cuando estaba vacante la sede, pero no llegó a obtenerse el beneplácito real ni las bulas apostólicas correspondientes ${ }^{3 !}$.

En 1518 D. Alonso de Aragón renunció al abadiato en favor del segundo hijo del tercer Duque de Gandía (D. Juan de Borja),D. Alonso de Borja, que

30 MASOliver, A.,op. cit., p. 71-86; ALTISENT, A., op. cit,p. 467-495.

31 Nos renitimos a los trabajos citados de J. TOLEDO GIRAU para más detalles, que no repetiremos. 
entonces era un niño de apenas siete años de edad. Se le nombró un administrador (D. Hernando Gómez, dean de Gandía) y fray Gaspar Bellver,doctor en Teología, monje de Valldigna,fué designado prior y procurador de la comunidad.Este último desplegó muchos esfuerzos para acabar con el sistema de las encomiendas en unas circunstancias dificiles para el monasterio y para el Reino de Valencia (las Germanías, saqueo de la abadía, conversión forzosa de mudejares, revuelta y huída de estos, ataques piráticos...), aunque en sintonía con la política del nuevo monarca, Carlos $V$, para extender y generalizar el sistema trienal y electivo de los abades frente a su carácter vitalicio como pilar de la reforma monástica ${ }^{32}$. Se llegó finalmente a un acuerdo con el Duque de Gandía por el que D. Alonso de Borja renunciaría a sus derechos a cambio de una pensión vitalicia de $\mathbf{4 0 . 0 0 0}$ sueldos;el convento confirmaría al citado Duque como su protector, abonandole a perpetuidad una pensión anual de 100 libras ${ }^{33}$ y la comunidad elegiría entre sus miembros al Abad para un período trienal. Don Gaspar Bellver fué elegido como tal de forma provisional y acudió a Bolonia y Roma a fin de obtener la renuncia al patronato por el emperador Carlos y las bulas de la Trienalidad Abacial por parte del Papa (17 de diciembre de 1529 y 1 de enero de 1530 ).

Desde esta fecha empieza el período conocido como de los Abades Trienales $^{34}$, si bien D. Gaspar Bellver, sin duda en mérito a la labor realizada, obtuvo el especial privilegio del Pontifice ${ }^{35}$ de poder ser abad durante seis trienios más si lo deseaba y era reelegido por la comunidad.Pero su labor como prelado fué muy conflictiva, precisamente en un momento en que el endeudamiento del monasterio era muy considerable. Favoreció a su hermano Juan y nombró Justicia Mayor del Valle a su sobrino Luis, quien abus6 de su autoridad y exigencias económicas provocando airadas protestas y tensiones entre los vasa-

${ }_{32}$ GARCIA ORO, J.,"La reforma de las ordenes religiosas en los siglos XV y XVI", en Historia de la Iglesia en España, dirigida por R. GARCIA VILLOSLADA, Madrid, 1980 (Biblioteca de Autores Cristianos),vol. 1II- ${ }^{\circ}$, p. $211-349$, especialmente p. 293-5.

3a Se trata de una confirmación, pues el acuerdo primitivo, motivado esencialmente por razones de defensa frente a los ataques corsarios, se remonta a 1520 (GASCON PELEGRI,V. "Capitulos para la salvaguradia y custodia de Valldigna en el siglo XVT", Primer Congreso de Historia del Pais Valenciano, Valencia, 1976, vol. III, p. 125-132.

34 No reproducimos diversos detalles biográficos de los mismos, para lo que nos remitimos a la obra citada en la nota 12 . Nos centraremos en aportar nueva informarción de origen archivístico, con interés en el ambito eclesiástico en relación a la historia de las ordenes religiosas y del Císter en particular.

${ }^{35}$ Así consta en la Bula de la trienalidad abacial, publicada por TOLEDo GiRAU, J., en su obra cilada sobre los abades comendatarios, p. 489-92.

Sobre cconomía Eclesiástica Hispania Sacra 49 (1997) 
$1 \operatorname{los}^{36}$. Se enemistó con el prior y un sector de la comunidad, quienes en diversos memoriales le acusaban de tibieza en el aspecto religioso, de incumplir determinadas normas conventuales, pero sobre todo de apropiarse de los ingresos del monasterio ${ }^{37}$. Dejó de abonar la pensión prometida al hijo del Duque de Gandía, por lo que fué encarcelado ${ }^{38}$, enemistandose con éste ${ }^{39}$. La visita del abad de Santes Creus en 1535 tuvo que esforzarse en apaciguar los ánimos ${ }^{40}$. Finalmente D. Gaspar Bellver renunció ante notario a la abadía en 1536, sucediendole fray Jaime Riera.

Poco antes,en 1531-32, el abad de Claraval, Dom Edme de Saulieu, había realizado un viaje por todos los monasterios y casas del Císter de España, preocupado por los aires de separatismo en Castilla y por la necesidad de vigilar y reformar muchas prácticas. Del mismo ha quedado la narración de su secretario Claude de Bronseval, la "Peregrinatio Hispanica". En Valldigna estuvieron desde el 29 de abril al 2 de mayo de $1532^{41}$. En el informe de la

36 Información variada procedente de la documentación privada del Duque de Gandía (AHN,Osuna,leg. 799), aunque con frecuencia sin fechar y no facil de organizar. Los abusos del abad y su sobrino respecto de los vasallos en Ibidem, $n^{\circ} 64$.

37 En un documento titulado "Cargos contra el Abad" y sin fecha (AHN,Osuna, Ieg. 799, n 96) se le acusa de gran número de faltas, entre cllas que dice misa de quince en quince días, que ha recibido monjes forasteros en el convento sin licencia, que ha dado oficios a extrafios, que su hermano y sobrino vinieron pobres al valle y se han enriquecido cometiendo multiples atropellos, que ha vendido la plata y omamentos del convento y sacristía, que ha interrumpido las limosnas y la hospitalidad,que se ha aprovechado de diversas cantidades pertenecientes al convento, que ha provocado varias vejaciones a los vasallos por las que han huido a Berbería, que se apropio de los bienes que estos abandonaron, etc.

${ }^{3 B}$ Así consta en un proceso entre el abad fray Jaime Riera y Fray Gaspar Bellver en 1538 (ARV,Cl,leg. 732,caja 1.906-07).

39 Bernat Cervero,"criado" del Duque de Gandía, que fué Justicia Mayor de Validigna a mediados de los años veinte dirá "de fray Gaspar Belver abbad de Valldigna tengo por el mayor mentiroso que aya en el mundo y que nunca dize verdad sino por error"; que se le ofreció para "que nos ligasemos el y yo y si lo haziamos seriamos señores de aquella tierra y hariamos quanto quisissemos";no guardaba la abstinencia , con frecuencia le hacia trabajar los domingos y fiestas de guardar en vez de servir a Dios, además de otros actiludes de avaricia(AHN,Osuna, leg. 799, n० 63). El Duque de Gandia hacía prometer a los arrendatarios de las rentas del monasterio a mediados de los años treinta que no consentirían que Bellver o "deudo suyo" residiese en el valle (lbidem, n' 100).

${ }^{40}$ En carta a los jurados y "consell" de Tavemes de 17 de agosto de 1535 el abad de Santes Creus,visitador de Valldigna, intenta calmar a los vasallos, pedirles sosiego y obediencia al abad, además de que le envien un memorial con sus quejas (AHN,Osuna, leg. 799, $\mathrm{n}^{\circ} 60$ ).

41 COChERIL, M.,"La peregrinatio hispanica de Frère Claude de Bronseval. Une visite refulière des abbayes cisterciennes de la Peninsule Iberique (1531-1533), Studia Monastica, Montserrat, 1961,vol. 3, p.179-213; Idem, Frére Claude de Bronseval. Peregrinatio Hispanica. Voyage de Dom Edme de saulieu, Abbé de Cairvaux en Espagne et Portugal (1531-1533. Introduction, traduction et notes,Paris, 1970, 2 vols.; BRONSEVAL, Claude, Viaje por la Valencia del siglo XVI, Valencia, 1993 (texto latino, traducción y comentarios de Francisco Calero y Daniel Sala). 
visita ${ }^{42}$ se ordena corregir algunos defectos observados, como la celebración diuma y nocturna de los oficios divinos, con devoción y detenimiento, siguiendo los cantos que son costumbre en la Orden. Que diariamente se celebre las misas previstas (a Santa María, la de difuntos...) y aquellos que no esten inscritos para ellas, celebren misa al menos tres veces por semana, asi como que los no sacerdotes comulguen todas las fiestas y domingos.Que se escojan confesores idóneos y capaces. Que se evite la ociosidad y esten ocupados en la lectura y en el trabajo manual. Que no se admitan novicios bastardos o hijos de judíos e infieles. Que siempre que esté reunida la comunidad haya algún prefecto para hacer las correcciones necesarias ,que todos los días se efectúe capítulo a fin de reconocer los defectos o faltas, asi como que se castigue a los que murmuran, siembran la discordia, los violentos o los rebeldes. Los hermanos comerán juntos en el mismo lugar y tiempo, en silencio y oyendo alguna lectura, sin comer carne en los días prohibidos. Tras recitar las completas, se retirarán en silencio a sus celdas y dormitorios sin comer.

Se insiste en la necesidad de la clausura: los religiosos no saldrán del monasterio sin licencia del Abad y siempre por causa necesaria; cuando salgan, no lo harán solos; no acudirán a otros lugares ni a casas ajenas, salvo autorización abacial y por motivo importante. A quien incumpla estos preceptos se le considerará "fugitivo" e impondrán duros castigos. Si tienen que salir del monasterio, no tendrán contacto con seglares, los cuales no seran introducidos en él salvo por motivo justificado. Deberán lavar sus ropas en el interior del convento y no enviarlas para que lo hagan otros fuera del mismo.

Que se abstengan de todo tipo de propiedad, y en particular de ahorros de dinero, pues todo lo que les es necesario les será provisto por el abad. Que no se reparta dinero para vestuario y otras cosas, sino que todo sea tenido en común y se distribuya según las necesidades. Dado que el monasterio tiene importantes deudas, se contentarán con la ración que se les dé y evitarán lo superfluo. Con todo, deberá practicarse la hospitalidad con quien se presente inesperadamente y distribuirse limosnas a los pobres según las posibilidades. Salvo en período de peste, que se les admita en el hospital para comer, dormir y descansar y especialmente se cuide de los enfermos.

Se insta al abad a que administre correctamente el patrimonio del monasterio y le exonere cuanto antes de sus deudas.Los adminmistradores le comunicarán sus balancess al menos cuatro veces al año, y al final de cada ejercicio se harán las cuentas generales de entradas y gastos, que se guardarán en los archivos. Igualmente deben anularse cuanto antes determinados contratos (arren-

\footnotetext{
42 Publicado y traducido en la última publicación citada, el original se encuentra en el AHN, Clero, pergaminos, carpeta $3.395, \mathrm{n}^{\circ} 11$.
} 
damientos, ventas, censos...) efectuados sin las formalidades debidas y perjudiciales para el monasterio.

Poco después, la Valldigna perdió el Priorato de San Bernardo de la Huerta o de Rascanya, situado al norte de la ciudad de Valencia. Fundado por el abad Saranyo y confirmado por el papa en 1388, dependía del mismo y había sufrido las secuelas de los comendatarios durante el siglo XV, encontrandose poco poblado y en estado bastante descuidado en los años treinta del siglo XVI. El proposito de la virreina $D^{2}$ Germana de Foix de fundar un monasterio de monjes jerónimos, fué continuado por su esposo el Duque de Calabria, quien puso los ojos en el citado priorato y tras convencer a Carlos V, obtuvo de Paulo III en 1546 la bula para extinguir la comunidad de San Bernardo e instituir en su lugar la de San Jerónimo, llamandose el monasterio a partir de entonces San Miguel de los Reyes. La apelación y ulteriores pleitos de la Valldigna resultaron inútiles y los jerónimos vieron confirmados sus derechos en $1570^{43}$. En cambio, en 1580 se le concedió el monasterio de Montsant, en la ciudad de Xátiva, cuando su reducida comunidad de religiosas, de vida austera pero anárquica, fue suprimida en aplicación de normas más rigurosas procedentes del Concilio de Trento y sus monjas trasladadas al monasterio de la Zaidía , en la ciudad de Valencia ${ }^{44}$.

Superada la crisis provocada por fray Gaspar Bellver, en 1558 volvemos a tener noticias de discordias internas dentro de la comunidad:el virrey de Valencia, Duque de Maqueda, recibe ordenes para que amenace con graves penas a todos los seglares, amigos y "deudos" del abad, fray Jaime Bellvis, a fin de que abandonen el monasterio, pues han impedido que el visitador cumpla con su deber. Además se acusa al abad de querer convertirse en perpetuo y por ello encontrarse en discordia con un sector de los monjes ${ }^{45}$. Con todo fray Jaime Bellvis fué suspendido durante seis meses de su cargo por el visitador de Santes Creus, pero apeló a la Santa Sede y obtuvo sentencia favorable prolongandose durante seis meses su mandato $(1556-1560)^{46}$.

Acabado el trienio de D. Juan Gutierrez en 1566 , la elección del nuevo abad, D. Juan Fano (segundo trienio) fué tensa y conflictiva. Surgieron roces y desavenencias entre los religiosos, hasta el punto que, enterado el virrey interino D. Juan Llorens de Vilarrasa,envió al monasterio a micer Christophol

\footnotetext{
${ }^{43}$ Referencia habitual en la bibliografia cilada, pero en particular GASCON PELEGRI,V., Sant Bernat de Rascanya.Florons del senyoriu valldignenc, Valencia, 1967,

${ }^{44}$ Entre otras fuentes, vease ARV,Clero,caja 2.075-76.

45 ARV, Real, libro 1.325, fol. 318. Carta de su alteza la Princesa Juana al Virrey, Valladolid, 24 de enero de 1558.

46 GASCON PELEGRI, V., Historia de Tabernes..., p. 153.
} 
Roig para asistir a la elección y sin inteferir en ella, procurar que se realice con tranquilidad, sosiego y según las prescripciones canónicas ${ }^{47}$.

Pero la comunidad estaba profundamente dividida y sus tensiones habían trascendido a los vasallos pobladores de los pueblos próximos. Al abad electo , apoyado por parte de la comunidad, se enfrentaba otro sector, en el que estaba el prior, el subprior, otros frailes,algunos seglares y sobre todo fray Hieroni Valls, hombre duro y vengativo al parecer de sus enemigos, quien llamó a un notario de Xátiva, Pere Gasch, a fin de que recogiese testimonios e informaciones sobre el incumplimiento por el abad de los mandatos de la última visita de Santes Creus ; se reunía con varios de sus partidarios en casa de una hermana suya en el contiguo lugar de Xara e implicaba en sus acusaciones a los propios pobladores, con lo que el tema iba adquiriendo trascendencia pública. Un testigo dirá que "li pareixia feyen alguna germania". No faltó algún enfrentamiento verbal con el padre Fano, con poco respeto y consideración a su dignidad. En las declaraciones de fray Miguel Xuxea,favorable al abad, se dice que "may ha vist la casa y religiosos y encara los vassalls en tanta fatiga com huy estan y mes que mes desque lo Rmm. Abbat de Sentes Creus sen es anat perque ha dexat la casa ab tanta confussio que recela nos perda tot per haver dexat tant poder com preten frare Hieroni Valls li ha dexat dit visitador per que diu q. pot castigar y acusar al monjes y al abbat lo que sea lansar a perdre la casa", o que "la casa esta molt divisa a causa de frare Valls perque amotina los huns contrals altres..."48.

No parece, pues, que la situación monacal de la Valldigna fuese muy encomiable por esos años. Impresión que se refuerza cuando en 1570 se efectuó, a instancia del arzobispado de Valencia, una inspección en las parroquias de los pueblos del valle, dependientes de los monjes, en la que se puso de relieve la ignorancia de los párrocos, el abandono de sus funciones pastorales, el incumplimiento de las prescripciones sobre dotación económica, etc.. Todo ello, junto con el problema de la titularidad de las antiguas tierras de las mezquitas o el privilegio del pago insignificante de diezmos, explica la enemiga del nuevo arzobispo , Juan de Ribera (1569-1611) ${ }^{49}$, quien deseoso de aplicar las nue-

${ }^{47}$ ARV,Real, libro 1330, f.9-14, citado por PILES ALMELA, M. A., El virreinato interino de $D$. Juan Llorens de Vilarrasa (octubre de 1563-Mayo de 1567), tesis de licenciaura inédita (Dpto. Historia Moderna, Un. de Valencia), p. 252-53, 4 de marzo de 1566. De hecho, era bastante frecuente que cl Virrey enviase un doctor de la Real Audiencia para que estuviese presente en la elección de abad y cvilase los altercados entre monjes (ACA, CA, leg. 651, $\mathrm{n}^{\circ} 76-2,23$ de mayo de 1591).

48 ARV,Clero, caja 2.105, Libro de Justicia de Cimat de 1566, anotación de 24 de abril de 1566, información de testigos que efectúa el Justicia Mayor a instancia del abad.Este y sus seguidores son críticos con el visitador, que a su parecer cometió diveros excesos. En cambio, Fray H. Valls es acusado de ser el mentor de aquel.

49 Vease el apartado III de este artículo.

Sobre economía Eclesiástica Hispania Sacra 49 (1997) 
vas directrices de Trento y reformar entre otros los monasterios, tuvo que chocar con la autonomía cisterciense, la autosatisfacción y el orguilo de saberse respaldado por importantes privilegios reales de la Valldigna. Mientras tanto, Felipe II impulsaba a través de sus embajadores ante la Santa Sede los proyectos de reforma religiosa en generaj y en particular de las órdenes regulares. Largo fué el esfuerzo por reformar el Císter de la Corona de Aragón, constituyendo una Congregación semejante a la de Castilla y no dependiente de superiores franceses, pero la resistencia de los afectados y los diversos intereses en juego imposibiliaron el éxito del intento hasta el reinado de su hijo y sucesor Felipe III ${ }^{50}$.

Pese a su carácter electivo y por un período temporal, el abad adquiría un gran poder no solo entre la comunidad sino sobre los pueblos sobre su jurisdicción como señor feudal.Todos los cargos de dirección del convento ${ }^{51}$ o del valle dependían de su autoridad. A veces, las revanchas o los favoritismos se hacían inevitables. Un ejemplo bastante repetido en esta época fue el nombramiento de seglares familiares o allegados para desempeñar el cargo de mayor poder e influencia sobre los vasallos después del abad, como el de Justicia Mayor, que además podía acarrear importantes beneficios económicos.Los abusos en el ejercicio de la jurisdicción, que siempre eran explicados por el móvil de obtener una mayor recaudación de penas pecuniarias,crearon malestar en la comunidad campesina y propiciaban pleitos entre el monasterio y los vasallos ${ }^{52}$

En los años ochenta del siglo, dos religiosos parecen controlar la vida del monasterio. Uno es D. José Garrigues, doctor en Teología, entre los hombres más cultos en ese momento en la comunidad, quien fué elegido abad por tercera vez para el período 1579-1582. Su sucesor el padre Pedro Castell no se sintí6 muy a gusto en el cargo, pues renunció antes de acabar su mandato, sucediendole D. Francisco Gil (1585-88),el otro líder, hombre de caracter fuerte , que nombró a su hermano Miguel Gil Justicia Mayor del Valle, puesto en el que permaneció hasta su muerte en 1593. Para el siguiente trienio (1588-91) fué elegido (y por cuarta vez) D. José Garrigues y le sucedió de nuevo D. Francisco Gil en 1591 para un segundo trienio (1591-1594). Desde esos años empezaron un sinfín de pleitos con los pueblos del valle que no acabaran hasta 1609 con la expulsión de los moriscos. En sus declaraciones de parte, los testi-

so GARCIA ORO, J.,op. cit, p. 303-337.MASOLIVER, A., op. cit., p. 44-52.

5 I Para el siglo XVI estan documentados el de prior, subprior, colector, "bosser" o bolsero y grangero.

\$2 Además del ejemplo ya citado del abad G. Bellver, podemos aludir a los siguientes Justicias Mayores:D. Juan Bellvis, hermano del abad J. Bellvis; Juan Gatiana, deudo de la hermana del abad Hieroni Valls; y Miguel Gil, hermano del abad fray Francisco Gil. 
gos favorables a los vasallos diran que entre estos dos hombres (Garrigues y Gil) había una "buena correspondencia" y que "tienen tiranizado al convento porque no hay frayle que les ose contradezir ni hosan dezir las cosas de razon porque son tambien muy rigurosos de condition",lo que saben porque "lo han oído decir a los frayles"s3.

Un informe del Consejo de Aragón de 23 de mayo de 1591 advierte de los claustrales que "no viven ni comen en común, ni acuden al choro, salen de casa sin liçencia, los mas celebran misa raras veces y pocos saben letras, los curatos de sus lugares se los reparten los religiosos y viven en ellos con ama y criados, y recogen a discolos y otros que toman por achaque el yrse a estar con ellos", urgiendo la necesidad de una reforma y reflexionado sobre como efectuarla ${ }^{54}$. Finalmente, y a requerimiento de Felipe II, el papa Clemente VIII expidió un Breve para que el Nuncio, o quien el delegase, efectuase una visita extraordinaria, rompiendo por tanto el procedimiento habitual, que correspondía normalmente al abad de Santes Creus. El Cardenal Riustiucio, protector de la Orden del Císter en Roma, escribirá una dura carta al abad de Poblet, sustituto por enfermedad de aquel, tachándole cuando menos de negligente por haber permitido que los monjes de Valldigna viviesen "con tanta relaxacion y dissolution" que hayan obligado al monarca a adoptar una solución tan drástica. En su descargo, defiende su actuación, resta importancia a los males atribuídos a Valldigna y hace una advertencia premonitoria, fruto de su experiencia: normalmente estas visitas extraordinarias "pocas vezes se pueden igualar los benefficios con los daños"'s5.

53 ARV, Cl, c. 2.212-13, posiciones 98 y 100 del interrogatorio de preguntas a instancias de Benifairo, 21 de enero de 1594. Lo mismo viene a decir una consulta sobre la visita del obispo de Utica de 27 de mayo de 1594 (ACA, CA, leg. 697, n० 7-3). Vid tambien ACA, CA, leg. 696, $n^{\circ} 4-2$ y 4-3).

54 ACA, CA,leg. 651, $n^{\circ}$ 76. Por ejemplo, trayendo al menos seis religiosos de Castilla, aunque oriundos de la Corona de Aragón,para visitar y reformar el convento; plantearse la posibitidad de trasladar la comunidad a Valencia (para que no esten tan alejados, cerca del mar, entre moriscos y puedan estudiar en la Universidad).

5s Relata el abad de Poblet que estuvo en febrero de 1591 en sustitución del abad de Santes Creus y por indisposición del mismo, acompañandole el Dr. Juan Sentis, canonigo de Lérida; "hallaron algunas insolencias graves, pero fueron corregidas"; presidio la elección de Abad (D. Francísco Gil),que obtuvo 32 votos de los 34 que concurrieron; sospecha que la Valldigna tiene enemigos y competidores "por la fama que tiene de rico como por aver de competir con muchos en differentes negocios q. se offrecen cada dia y no faltaran de los propios religiosos que por averles su perlado castigado o por otros respectos que suele aver en monasterios trienales procuran estas novedades"; considera que los descuidos de los monjes no han llegado "a termino de aver de perder la confianza de enmienda y ay muchos que aman la virtud", defendiendo en cualquier caso su labor y entendiendo no justificada la decisión adoptada (ARV,Cl, c. 1.969-70, 28 de septiembre de 1591). La remisión del Breve de su santidad dirigido al Nuncio para visitar Valtdigna en ACA,CA, leg. 696, $n^{\circ} 4-1$, carta del embajador Duque de Sesa de 14 de marzo de 1592).

Sobre economía Eclesiástica

Hispania Sacra 49 (1997) 
Conocida la noticia, no solo el convento sino también diversas instituciones y personalidades valencianas reaccionaron solidariamente suplicando inutilmente su anulación ${ }^{56}$. El Nuncio Camilo Caetano delegó en D. Malachias de Asso, abad de Rueda y obispo de Utica, la misión de realizar la reforma con todo el apoyo real ${ }^{57}$. Con ello comenzó uno de los episodios mas conflictivos y tensos de la vida monástica valldignense , conocido como la "Visita del Obispo de Utica"s8.

Comenzó la visita en 1592 y el Obispo de Utica debió permanecer en el monasterio hasta mediados de 1594, acompañado de algunos monjes forasteros. En aquella se puso de relieve que vivían con mucha relajación y era necesaria la reforma, pues no se guardaban los estatutos de la Orden, acudían con tibieza a los ejercicios espirituales y a la celebración de los oficios divinos, "entre si estavan divididos en dos vandos y las cabeças dellos se partían los trienios y para grangear los votos a los de su parcialidad los dexavan vivir con toda libertad y a los otros persiguian"; "de religiosos les quedava poco mas que el nombre", pues cada uno tenía patrimonio propio que gastaba libremente,no comían ni dormían en común, salían del monasterio a todas horas solos y sin licencia "y en el monasterio admitian conversaciones desonestas", además de que los abades administraban mal la hacienda monacal y atropellaban a los vasallos, a quienes multaban fuertemente y estaban en pleitos con ellos ${ }^{59}$. Por su parte, según la versión de los religiosos, hizo la visita con todo rigor y "no hallo culpa que no fuese de consideración", desterró a las "mejores cabezas" a otros conventos y trajo religiosos forasteros, introdujo en el monasterio un alguacil y corchetes seglares como medida intimidatoria y con incremento de los gastos, detuvo y proces6 al abad y "no hay quien ose hablar por q. con la

\footnotetext{
56 Carta del abad F.Gil al Rey y al Vicecanciller de Aragón; del Duque de Gandía, D. Carlos Borja, Protector de Valldigna, y de los Diputados de Valencia al Rey (ARV,Cl, c. 1969.70, octubre de 1591). Estos biltimos refieren que los monjes estan molestos porque su credito esta tan bajo que su Magestad haya pedido al papa un breve para que pueda visitarlos persona distinta al abad de Santes Creus, juez inmediato y visitador de Valldigna y del de Poblet, vicario general de la Corona de Aragón y por consiguiente visitador general de ella.

57 Abundante documentación sobre la visita en ARV, Cl, c. 1.952-53. Entre otras, cartas del Rey y del Nuncio dando poderes al visitador y ordenando que se le obedezca.

s8 Una crónica y abacilogio de Valldigna, escrita probablemente por un monje a mediados del siglo XVIII(vid. nota 12) relata "que fueron muy grandes (las ninas y quiebras) y dieron bien que hazer.Estos dafios si no es quien los vee, no sabe lo que son, ni se lo puede persuadir aunque se lo nefieran, solo la experiencia tiene la eloquencia para explicarlos y los da a entender bien". Recuerdese que poco antes, en 1587-88, había comenzado la visita al importante monasterio de las Huelgas, con no pocos problemas (GARCIA ORO, J., op. cit., p. 338).

59 AHN,Consejos, libro 2.397, fol. 249-250. También en ACA, CA, leg. 697, n 7-3. Diversos mernoriales y escritos de los vasallos quejandose al Obispo de Utica de situaciones concretas en ARV, Cl, c. 1.954).
} 
obediencia y violencia van del todo oppresos" prendieron acciones legales, pero la tensión debió alcanzar su punto máximo cuando al comenzar el año 1594 observaron no solo que no se celebraba la elección de nuevo abad trienal, sino que posteriormente se prorrogaba sistemáticamente ${ }^{6 i}$.

En 15 de junio de 1594 Felipe II ordena a los religiosos de Valldigna que, siendo necesaria la reforma, cumplan las "ordinationes" efectuadas por el vísitador, el cual pronto deberá incorporarse a su nuevo cargo como obispo de Jaca. Ha acordado con el Nuncio que hasta que se resuelvan las cuestiones pendientes, quede "suspensa" la visita, continue como presidente de la comunidad fray Bartolomé Ximeno (monje del monasterio de Santa Fé que acompañó al Obispo de Utica), al que deberán obedecer, asi como a los religiosos que vengan de otros conventos para ocupar los distintos oficios ${ }^{62}$. En 18 de junio de 1594 se prorrogaba por otros seis meses la elección abacial, medida que se continuará sucesivameñte ${ }^{63}$.

De hecho Felipe II comprende que "aunque el visitador a puesto el remedio que ha podido, se ve que la causa del daño passado se queda en pie y que no quitandole de quajo esta en la mano la recayda y que del tiempo y hazienda que se ha gastado en la reformacion no se haura sacado sino hazerlos mas cautelosos para encubrir sus faltas".Por tanto, es necesario cambiar el "sistema"y requiere del embajador en Roma que obtenga del Papa autorización para que los abades de Valldigna sean perpetuos, con lo que se acabarían las inquietudes y aspiraciones para ser elegidos (con las divisiones y bandos entre monjes), e incluso algunas personas sugieren que, puesto que los Reyes de Aragón fundaron los monasterios, correspondería al Rey "presentar" al abad de Valldigna; que se reformen los curatos; y dado que, muchos de estos problemas son generales a otras abadías de la Corona de Aragón, debería crearse aquí, como ya se ha hecho en Castilla y Portugal, una Congregación, que con sus propios organismos (capítulos generales y provinciales, deffinidores, visitadores) es más útil para la reforma de costumbres, independiente a su vez del abad de Císter que reside en Francia y nunca visita estos reinos; igualmente era conveniente cerrar algunas casas que tienen pocos religiosos y con sus rentas fundar colegios y universidades para que estudien los monjes ${ }^{64}$.

60 De un memorial contra el "Bisbe de Utica", sin fecha y dirigido al papa (ARV, Cl, c. 1.954).

6 La citada crónica afirma que los monjes recelaron que la facultad de elegir abad tenía que revocarse "como en effecto se revocó".

62 ACA, CA, leg.680, $n^{\circ}$ 104-15, 15 de junio de 1594; Ibidem, leg. 697, $n^{\circ}$ 7-3 y 7-5. El obispo de Utica expulso durante un tiempo al último abad, fr. Francisco Gil.

63 ARV, Cl, c. 1.952-53 y 1.954, con varias referencias a aplazamientos de la elección.

64 AHN, Consejos, libro 2.397,fol. 249-250, cartas que en 16 de enero de 1595 el Rey envió al embajador en Roma, y otras posteriores en las que se manifiesta que no ha recibido respuesta de todo

Sobre economía Eclesiástica Hispania Sacra 49 (1997) 
El problema de la visita de Valldigna se conecta, pues,con los intentos por parte de la Corona de reforma monástica general y en particular del Císter, buscando dificultosamente la creación de una Congregación propia de la Corona de Aragón, independiente del Císter frances, que facilite la solución de las prácticas viciadas. Creemos que acertadamente se ha visto la dura resistencia de la comunidad valldignense al Obispo de Utica como una toma de posición frente a los intentos reformadores y congregacionistas del monarca, de forma paralela igualmente a la actitud de oposición que adoptó el monasterio de Poblet ${ }^{65}$. Pero el problema debía dilucidarse ante la Santa Sede, donde ejercían también sus presiones contrarias a la Congregación el Protector de la Orden del Císter y el embajador de Francia.

La sucesiva suspensión de la elección de abad y la continuidad de la presidencia de fray Bartolomé Ximeno đebió ser un signo inequívoco y alarmante para los monjes valldignenses. Sus acciones legales obtuvieron finalmente autorización para efectuar la elección, lo que hicieron el 13 de diciembre de 1595 en la persona de fray Bartolomé Serrano. Contrariado el monarca por ello, intentó suspenderla nuevamente, interponiendo recurso, aunque su orden llegó tarde. Impugnada la elección del abad Serrano, será posteriormente, en 1596, confirmada por el papa Clemente VIII, quien estimó los recursos presentados, confirmó la elección trienal de Serrano y al parecer desvirtuó la visita del Obispo de Utica ${ }^{66}$.

Nada nos ha llegado del viaje a España en 1603-1604 de D. Edmundo de la Croix, abad de Citeaux, preocupado por el alejamiento castellano y los aires de la nueva congregación aragonesa, y cuyo itinerario, descrito por B. Joly, pasó

ello, asi como copia enviada al Virrey de Valencia. Los tres puntos de reforma citados aparecen reiteradamente en las consultas y documentación de la ćpoca en el consejo de Aragón, no ya circunscritas a Valdigna, sino a todos los monasterios del Cister de esta zona (ACA, CA, 697, n० 7-3, 7-4 ,opiniones de los virreyes y obispos; 7-7, informe de Pedro Sans; y 7-8, todo ello en 1594-1595).

6s MASOLIVER, A., op. cit., p. 52, nota 93, donde se recoge tal idea de E. Fort i Cogul, al marginar en la visita al abad de Santes Creus y al de Poblet, Oliver de Boteller. La oposicí́n de este monasterio a la Congregación, por cjemplo,en ALTISENT, A., op. cit., p. 479).En el contexto de esta contienda en torno a la Congregación hay que entender la carta y memoriales que en 1594 envió el abad Oliver de Poblet al Rey en respuesta a una consulta sobre si se autorizaba una visita del General de la Orden del Císter en sus reinos. Según su parecer, no solo Poblet sino en general todos los monasterios del Císter aragonés gozaban de una buena situación, estaban muy reformados y no convenía por tanto cambiar el sistema imperante (ARV, Cl, c. 1.969-70).

to La carta del Rey prohibiendo toda elección lleva fecha de 6 de diciembre de 1595; suspendia la eficacia del Breve enviado por el Nuncio y disponía que si acaso se había efectuado ya la elección ,se anulase y se repusiese al presidente hasta nuevas instrucciones (ARV, Cl, cajas 1.952-53 y 1.954). Desconocemos el alcance de la decisión papal respecto de la visita; la cronica citada solo dice que ésta se suspendi6; de cualquier forma, la confirmación en el cargo de abad de un monje del convento iba a permitir suavizar o alterar progresivamente los mandatos de tan aborrecida visita. 
y visitó Valldigna ${ }^{67}$.Pero el sosiego no imperaba en la vida monástica. La comunidad estaba dividida nuevamente en dos "parcialidades" al final del trienio del abad D. Rafael Lluqui (1604-1607).Una de ellas reclamó y obtuvo una visita extraordinaria que protagonizó D. Juan Salinas, prior de Montesa, en la segunda mitad de 1607 , quien pondrá de relieve la mala administración económica y "relaxation de su persona"; ante su presencia se efectuó la elección satisfactoria de un nuevo abad, D. Juan Costeja(1607-1608)68. Pero la otra "parcialidad" dirá del visitador que era hombre "apasionado", que asumió los criterios de un sector de religiosos, a quienes dió todos los oficios, impidió votar en la elección abacial a fray Pablo (Perez) Arnal (su figura más destacada), hombre ejemplar, por lo que aquella es nula; impide que salgan correos para que no la puedan recurrir y no da licencias para salir del convento; viven como propietarios, defraudando al monasterio en sus propios, con mal ejemplo "et luxuriose". Se intentó calmar los ánimos, acentuados con la visita, mediante la renuncia de D. Juan Costeja a favor del nuevo visitador fr. Manuel Perez de Heredia, abad del Valparaíso ${ }^{69}$. La crónica admite que se acallaron las inquietudes y fué elegido D. Juan Serra (1608-1611) para la dirección de la comunidad. Pero una carta de Felipe III al virrey Marqués de Caracena en 6 de junio de 1609 manifestará abiertamente que de nada han servido dos visitas a Valldigna, pues los religiosos viven en mayor relajación que nunca ${ }^{70}$.

El Breve de 19 de abril de 1616 del papa Paulo V establecía la Congregación de la Corona de Aragón, poniendo fin a un largo debate que había suscitado tantas gestiones diplomáticas como pasiones entre los religiosos. Para unos era el medio para la definitiva reforma monástica del Císter, para otros ésta, salvo excepciones (entre ellas la Valldigna), ya se había realizado y se producía una escisión innecesaria de la Orden, que presagiaba claros interven-

67 MASOLJVER, A., op. cit., p.54-56. ALtiSENT, A., op. cit. p. 479, quien le atribuye además el propósito de convertir en perpetuos atgunos abades trienales, como en Valldigna. V. Gascón alude a que en 1604 el padre D. Bartolomé Serrano fué elegido abad por segunda vez, y que fué designado para dos trienios por el generalísimo de la Orden, aunque murió al poco tiempo (op. cit., p. 178).

68 Según Salinas, era un hombre ejemplar, votado por 39 de los 45 monjes electores. Salinas $a b r i o$ diligencias, inculpo y castigó a varios frailes (cita a siete, más otros dos que huyeron con dinero del monasterio) al destierro en otros conventos, suspensión de voz activa y pasiva y reducción de monje a fraile lego. Su gestión tenía el beneplácito del consejo de Aragón (ACA, CA, leg. 866, 12-1 a 12-7) y del arzobispo de Valencia, Patriarca Ribera, largamente enfrentado con la Valdigna, de la que dice que hace años que necesitaba una reforma y aprovecha la ocasión para solictar al Rey que anule el sistema electivo de abad (Ibidem, leg. 702, $n^{\circ} 15,14$ de febrero de 1608).

69 ACA, CA, leg. 866,12-4,memorial del monje fr. Baptista de Lasa, de 22 de diciembre de 1607 ("fundado en pasión", según el Patriarca) y la citada crónica de Valldigna.

70 AHN,Consejos, libro 2.401, f. 179.

Sobre economía Eclesiástica

Hispania Sacra 49 (1997) 
cionismos estatales ${ }^{71}$. En este proceso, sobresalen los esfuerzos favorables de Sebastian Bonfill como la resistencia del abad de Poblet, D. Simon Trilla. Todos debieron paulatinamente adapatarse y aceptar la nueva estructura, ya descrita en líneas generales( no independencia respecto del Císter francís, Capìtulos Provinciales, Vicario General electivo, abades cuatrienales electivos entre una terna externa al monasterio,elaborada por los padres definidores y el Vicario, lo que limita el poder decisorio de los monjes...). En un capítulo celebrado en Rueda en 1626 se aprobaron los Estatutos (Definiciones)de la Congregación. En ellos se regularán tanto los aspectos organizativos (elecciones, cargos, ternas de abad, capítulos, Vicarios Generales..), como la espiritualidad, con Ja reafirmación de la Regla Benedictina y alguna escasa aportación de las corrientes procedentes de la "Devotio Moderna", además del horario (oficios divinos, misas, oraciones, descansos...).Algo más tarde, en 1634, se le unirán los monasterios navarros ${ }^{72}$.

Pocas son las noticias que tenemos de la Valldigna en las primeras décadas de esta nueva andadura. Sin que hayamos encontrado documentación que lo confirme, parece como si tras los agitados episodios anteriores, una cierta calma y sosiego caracterizase la vida de la comunidad a medida que se van aplicando las nuevas disposiciones congregacionistas. Además, el monasterio se encontraba fuertemente endeudado y tenía que hacer frente a la dificil repoblación de sus señorios despoblados por el extrañamiento morisco en una época de crisis económica. Así se refleja, por ejemplo, en la escusa a un pago ordenado por el Rey en $1616^{73}$. Al mismo tiempo, la Congregación era más costosa de mantener que el anterior esquema organizativo ${ }^{74}$. Ya hemos visto como

1 Obsérvese, por ejemplo, el distinto criterio de dos monjes, ambos oriundos del Poblet contemporáneo:A. ALT1SENT (op. cit., p.480-481), para quien la Congregación era de hecho innecesaria, y el de A. MASOLIVER (op. cit., p. 156-157), quien la considera necesaria y positiva, aunque con matices. Un documento, aproximadamente de 1612 y procedente de Poblet, aportando argumentos contra la erección de la Congregación, cita la Valldigna y Santa Fe, como unicos monasterios que , a la vez, se hallan relajados y son trienales, frente a los demás donde predominan los abades perpetuos (MASOLIVER, A.op. cil.,p. 64).

72 MASOLIVER, A,, op.cit, p.125-142. Desde luego predomina el sentido genuinamente benedictino con la importancia del oficio divino, que ha ido postergando el trabajo manual. Sobre la incorporación de los navarros (Ibidem, p. 121 y ss.).

73 El abad manifiesta en carta de 2 de diciembre de 1616 la imposibilidad de pagar 260 libras al padre Sebastian Bonfill por la estrechez econónica por la que atraviesa el monasterio, relacionada con las consecuencias de la expuisión de los moriscos y amenazas continuas de embargos por parte de los acreedores (MASOLIVER, A., op. cit,, p. 322). Aunque podemos considerar la misiva exagerada e interesada, de hecho no era holgada en ese momento la situación del convento.

${ }^{4}$ En los años ochenta del siglo XVI el monasterio consignaba entre los gastos, 19 libras, 3 sueldos y 4 dineros para la contribución ordinaria del general de nuestra orden del Císter (ARV, Cl, c. 2.705-2.706, relación de ingresos y gastos, año 1582), a lo que quizá hubiese que añadir los gastos ocasionados por las visitas cuando se produjesen. En una relación de gastos de 1678-1682 se anotan 
disminuye el número de religiosos. Como incidentes solo cabe reseñar la impugnación en 1625 del nombramiento de $\mathrm{D}$. Juan Salinas (el mismo conflictivo visitador de 1607) como Vicario General y visitador, en perjuicio de Valldigna y en contradicción con las normas estatutarias de la Congregación ${ }^{75}$. Durante este tiempo destacan las personalidades de $D$. Jaime Torres, quien se esforzó en mejorar la situación economica, y de D. Nicolas Talavera y Castellet, elegido en dos ocasiones Vicario General ${ }^{76}$.

Desde los años cuarenta, D. Rafael Trobado y Figuerola, de brillante trayectoria intelectual, se convierte en el hombre clave del monasterio y, al mismo tiempo, de la Congregación del Císter de la Corona de Aragón y Navarra. Rector del colegio de Huesca (1640-1644), definidor desde 1642, abad de Valldigna y Vicario General luego (1644-1649), definidor en el siguiente cua trienio, otra vez abad en 1652-1656, nuevamente definidor en 1656-1660, alegido abad por tercera vez en 1660 y Vicario General por segunda (16601665), para luego continuar como definidor. Desde 1640 hasta su fallecimiento en octubre de 1668 se convierte en el hombre más brillante e influyente del monasterio, a cuyo alrededor se configura una poderosa y mayoritaria "parcialidad", que suscitó una oposición dentro de la comunidad, entre la que destaca el setabense fr. Pedro Galiana, hombre también de ciertos estudios; pero igualmente es un personaje clave en la Congregación, en la que como Vicario y definidor tiene un peso fundamental en la elaboración de ternas para las elecciones de prelado en los distintos monasterios, con lo que extiende y aumenta su poder en la orden del Císter de la Corona de Aragón y Navarra. Podemos solo recordar, en esta larga trayectoria, los momentos de tensión de 1648-1649, cuando un sector del claustro le ataca gravemente al final de su primer período de gobierno y le acusa de perpetuarse en los cargos, retrasando la celebración del capítulo provincial 77 ; las duras críticas de 1656 por parte de monjes de Poblet y de la propia Valldigna, que mueven a la Corona a iniciar una investigación, $\mathrm{o}$ los momentos previos al capítulo provincial de Veruela de

anualmente 285 Libras y 10 sueldos para el Colegio de San Bernardo de Huesca, además de 350 libras y 18 sueldos "por el repartimiento de los gastos de la Congregación cistercienșe de la Corona de Aragón, gastos de visitas y gastos del Capitulo Provincial" (Ibidem, caja 2.075-2.076).

$75 \mathrm{Si}$ bien Juan Salinas (a veces, Salines)era prior de Montesa, ésta no era uno de los monasterios de la Congregación en el Reino de Valencia; le correspondía la elección a un valenciano, que fuese abad, condición que tampoco tenía el electo; además fué elegido en Barcelona (Nazaret), "a hon tenia y te los amichs y valedors y compatriotes..." (ARV, Cl, c. 1.969-1.970). Salinas murió el 11 de noviembre de 1626 y fué elegido Vicario General el abad de Validigna fray Nicolás Talavera (MASOLJVER, A., op. cit., p.117-118, 126, nota 5).

76 El primero fué abad en $1620-1624$ y 1628-1631, affo en que falleció; el segundo en 16241628, en 1631-1632 a raíz del fallecimiento de Torres, y en 1636-1640, siendo elegido Vicario General de la Congregación en 1626 y en este último período abacial.

$7 \mathrm{ACA}, \mathrm{CA}, \mathrm{leg} .696 \mathrm{n}^{\circ} 55,1$ a 56,1. 
166578. Para sus partídarios, Trobado se convertirá en la "mayor honra" de Valldigna e incluso de la Congregación; para otros, es un "tirano" que tiene sojuzgada a ésta durante más de veinticinco años, hombre de mala vida y ninguna virtud.

Pero al mismo tiempo, la situación del monasterio se aleja bastante del ideal de perfección regular. Es escasa la clausura, los monjes salen mucho y libremente de su recinto, tienen contactos usuales con los vecinos de pueblos próximos, algunos viven en Valencia o en los pueblos, se ocupan en oficios impropios de religiosos (Justicia Mayor, colector de rentas...); otros son titulares perpetuos de parroquias, donde viven de forma independiente, con sus propios bienes y criados, al margen de la abadía;no se cumple el voto de pobreza con la permisión del peculio particular; es mucha la ignorancia y poco el estudio, como escasos son los oficios divinos, la oración y el silencio, muy limitada la vida comunitaria, casi abandonado el trabajo manual y bastante la ociosidad de los conversos,etc., sin contar la crispación interna que crean las parcialidades (clientelismo, tolerancia en las costumbres y reparto de cargos a los fieles, murmuraciones, críticas, castigos a contrarios....).Este fenómeno de tibieza y casi total abandono de los ideales ascéticos era bastante general en casi todas las casas de la Congregación, donde además no faltaban algunos casos de escándalo y amancebamiento, si bien con caracter excepcional. Esta situación no es un fenómeno original, pues ha sido constatado con carácter global en los monasterios de benitos y bernardos (entre otros) de toda la península de manera muy patente a fines del siglo XVII, aunque quizá estuviese más acentudado en el Císter aragonés ${ }^{79}$.

Consciente el Consejo de Aragón (dirigido desde 1652 por el valenciano D. Cristobal Crespí de Valldaura) de este problema, fracasados algunos intentos de mejora y escéptico ante la posiblidad de una regeneración "desde dentro"(siguiendo los estatutos propios de la Congregación, pues un intento de visita eficaz quedaría pronto neutralizada), decidió actuar "desde fuera" y optó por organizar una visita extraordinaria a cargo del monje cisterciense castellano fr. Tomás Gómez. Para ello obtuvo una comisión del Nuncio (11 de junio de 1665), amparándose en que éste había recibido la jurisdicción sobre todas las ordenes religiosas ("religiones") mediante la Bula de 12 de septiembre de

\footnotetext{
78 Vease, vg. el Contramanifiesto de D. G. Costa, $n^{\circ} 80$ y ss. (Biblioteca Nacional, 2/45.872).

79 En colaboración con F. ANDRES ROBRES y R. BENITEZ SANCHEZ-BLANCO preparamos un libro sobre la visita de $1665-1668$ y sus antecedentes, al que me remito para ulterior desarrollo expositivo, precisión y matización conceptual, así como para su fundamentación archivística. De todos modos es necesario aludir al manuscrito de Gómez sobre la visita (AHN,Consejos, leg. 49.904), a la documentación del Consejo de Aragón (ACA, CA, leg. 680, 697, 914...), a los memoriales impresos de Trobado y los encontrados en ARV, Cl, c. 1.952-53 y 1.954, principalmente.
} 
1661 del papa Alejandro VII. Si bien podía haberse dirigido a cualquier monasterio, se escogió la Valldigna como forma de neutralizar a Trobado.

La resistencia ofrecida a esta visita (1665-1668) fué impresionante, con una multitud de matices y detalles que no podemos precisar aquí. La gran mayoría de religiosos la tildaron de ilegal y contraria a sus Definiciones y privilegios, le negaron la autoridad al visitador, quien tuvo que recurrir a la fuerza armada, enviar presos a Madrid al abad D. Jaime de la Tonda, al Vicario General y al propio Trobado, detener a otros en las cárceles del monasterio o en otros recintos; otros monjes huyeron y conspiraron siempre contra ella. La Congregación pronto se sintió amenazada y solidaria, interponiendo una apelación ante el Nuncio para paralizar la comisión; éste la admitió solo en sentido devolutivo, pero no en el suspensivo, a lo que creían tener derecho los apelantes;en reacción, presentaron un "recurso de fuerza" ante el Consejo de Castilla, quien al admitirla a trámite creó un problema de competencia institucional entre Consejos (Aragón y Castilla). La sociedad valenciana en general (la Real Audiencia, la Diputación, los diversos sectores de la ciudad de Valencia, la duquesa de Gandía...) se mostró mayoritariamente contraria a lo que, en un doble sentido de "inconstitucionalidad" y de ofensa "nacional", se llamó "visita castellana". Solo a duras penas fr. T. Gómez consiguió introducir algunas reformas, y en miras a su consolidación obtuvo la autorización para que acudieran a Valldigna como "refuerzos" ciertos frailes descontentos de otros monasterios, especialmente de Santes Creus y Santa Fé. Obviamente, esta visita avivó al mismo tiempo las esperanzas y las críticas de todos los religiosos contrarios al estado actual de sus conventos.

A pesar de las dificultades encontradas, el Consejo de Aragón solicitó al nuevo papa Clemente IX, en julio de 1667 , la confirmación de la comisión dada a Gómez y su prórroga (extensión)para visitar otros monasterios de Ia Congregación aragonesa. Se hizo eco de la súplicas para acabar con las elecciones de abad o al menos mediatizarlas, en el sentido de que en mayor o menor grado fuesen elegidos por la Corona como forma de acabar con los bandos o facciones. No obstante, ante la complejidad de este proyecto y la tardanza en obtener la pertinente aprobación del Pontificado, el Consejo quiso influir por medio del obispo de Albarracín en el capítulo definitorio de la Congregación que debía celebrarse en el verano de 1668: este prelado recibió instrucciones para vetar a algunos religiosos en las ternas para futuros abades, a fin de marginar definitivamente a ciertos elementos de la dirección de las comunidades y romper la "parcialidad" dominante. Pero el Vicario General y los principales hombres de la Congregación protagonizaron una auténtica oposición y revuelta, tanto en el ámbito procesal como político,y se refugiaron en Fitero (Navarra, Corona de Castilla) a fin de huir de la competencia del Consejo de Aragón. 
Los múltiples memoriales enviados a la Reina $D^{a}$ Mariana de Austria, las presiones palaciegas, los escándalos ocasionados impropios de la vida religiosa (prisiones de frailes,monjes huídos, intervención de la fuerza armada,y en particular el altercado de la Zaidía el 10 de mayo de 1668 ....), hicieron intervenir a la Corona a lo largo del verano de 1668 , neutralizando las intenciones del Consejo de Aragón. En su opinión la reforma de los monasterios y la corrección de los excesos de los monjes debía proseguirse "por los modos legítimos". En consecuencia, ordenó dar por acabada la visita de Valldigna, que volviesen el abad y los religiosos huídos, que se hiciese cargo de su gobiemo ellos mismos, que partiesen a sus respectivas casas los frailes forasteros, que no se inmiscuyesen o limitasen la libertad de los definidores en la elaboración de las ternas ni se vetase practicamente a nadie, que se efectuasen las oportunas elecciones como correspondía, que se advirtiese al embajador en Roma que desistiese de las acciones emprendidas para la extensión de la visita a otros monasterios, etc.. Con estas medidas el monasterio valldignense volvió a la normalidad y en los procesos electorales correspondientes de nuevo se impuso la "parcialidad" tradicional: D. Francisco Monreal como nuevo abad (1668), uno de los principales opositores desde la ciudad de Valencia y desde su refugio como confesor del monasterio de monjas de la Zaidía, y fray José Corredor, monje de Santa $F e$, varias veces abad y Vicario General, auténtico delfin de Trobado, fué elegido definidor por Aragón en mayo de 1669, y poco después se convirtió tambien en Vicario General(1672-73).

Como es fácil suponer, la "visita castellana" fué un profundo revulsivo para el monasterio. Si su economía había alcanzado un cierto equilibrio con anterioridad, los muchos gastos producidos le ocasionaron un considerable endeudamiento. Este no se alivió durante el cuatrienio siguiente de F. Monreal, quien siguió prácticas irregulares en la gestión económica, con lo que se ganó la enemistad del claustro ${ }^{80}$. Las décadas posteriores parecen entrar en un remanso de paz tras las tormentas anteriores. Según nuestra información, los abades se centran en la reconstrucción del templo (derribado por un terremoto en 1644) y en aliviar la situación financiera, sin que conozcamos ningún incidente interno salvo el pleito de los rectores de las parroquias ${ }^{81}$.

80 Durante la visita se suscribieron más de 10.000 L. en censales, más un préstamo posterior de 2.000; hacia 1680 el total de la deuda se cifraba en 16.696 L.. La gestión y gobiemo de Monreal provoco un motín frustrado de los vasallos en 1669 y concilo la critica de la comunidad, quien le acusó de apropiación indebida de $8.703 \mathrm{~L}$. de rentas monacales en 1674; tras dos fallos condenatorios dentro de la Congregación, apeló al Nuncio quien finalmente le absolvió en la sentencia de 27 de junio de 1680 (ARV, Cl, c. 2.041 y 2.087, 2.088-2.089).

s) Son los mandatos de Fco. Espi, Raimundo Sanz, los dos cuatrienios de Vicente Lloret, quien Ilegó a ser elegido Vicario General, J. Espi, P. Saurina y J. Castillo (GASCON, V.,op. cit., p. 200-201). Para las parroquias, vid infra. 
Finalmente, cabe aludir a los mandatos de la visita de D. Eugenio de Arlegui, abad del monasterio de San Salvador de Leire, efectuada en 1698, sin que nada en ellos parezca salir de lo normal. Se insiste primeramente en la práctica esencial de los oficios divinos, en su asiduidad, cuidado y orden, de los que solo algunos religiosos ancianos podrían eximirse excepcionalmente ; de la atención a los jóvenes, novicios y conversos, a los que hay que seleccionar adecuadamente y enseñar posteriormente, huyendo de toda ociosidad; de las formas y modos de corregir las culpas y faltas que se vayan produciendo; debe cuidarse la "vestición" tradicional en color blanco, sin permitir que nadie vista según su gusto;se recuerda con rigor el silencio nocturno de los religiosos en sus celdas, de las que no podrán salir; que no se franquee con facilidad la entrada de seglares en el refectorio, así como que se vigilen las compras que efectua el padre "cillerero" y no se den muchas licencias para salir del convento, además de otras prescripciones sobre predicadores, confesores, ordenandos...y sobre el gobierno temporal del monasterio ${ }^{82}$. Son correcciones sobre las actitudes tibias y acomodaticias de la vida monástica, sin grandes problemas. Los principales cargos de la comunidad son, desde luego, el abad, seguido del prior, subprior, presidente, procurador, colector mayor, colector de Tavernes, bolsero, portero, granjero de Benivayre, síndico de Valencia, gobernador..., además de los rectores de las parroquias ${ }^{83}$.

\section{III) LAS PARROQUIAS DEL VALLE: SU PROVISIÓN Y DOTACIÓN}

Ajenas a la vida monástica, aunque no totalmente desligadas de ella, las parroquias de las tierras contiguas al monasterio, y que constituían su señorio, se convirtieron en fuente de conflictos a partir del siglo XVI y merecen una cierta atención.

Poco después de la fundación del monasterio y por intercesión del rey Jaime II, el obispo y cabildo de Valencia concedieron perpetuamente en 1301 al abad el derecho de presentar un presbítero secular para cubrir la parroquia del Rafol, único lugar poblado por cristianos en el valle de Alfandech o Valldigna

y con jurisdicción sobre todo él. Aprobado por el obispo el clérigo propuesto, el convento (como perceptor de todos los diezmos y primicias del valle) se comprometía a abonarle 520 sueldos anuales para su mantenimiento. No obstante, dado que con esa cantidad apenas podía mantenerse el párroco y que por las diversas dificultades que atravesaba (guerra castellano-aragonesa, huí-

\footnotetext{
82 ARV, Cl, c. 1954.

83 Veanse, por ejemplo, las relaciones de religiosos en los inventarios del siglo XVIl (ARV, Cl, libro 3.953).

Sobre economía Eclesíática Hispania Sacra 49 (1997)
} 
da de vasallos...) mal podía el convento pagarla, solicitó y obtuvo del obispo en 1369 que en el futuro la parroquia estuviese provista por un monje del mismo y mantenido como los demás miembros de la comunidad ${ }^{84}$.

Esta situación se vió fuertemente alterada cuando en 1525 se ordenó la conversión forzosa al cristianismo de todos los mudéjares, a los que, devenidos en "cristianos nuevos", era necesario dar asistencia pastoral. La reforma parroquial de 1534-1535 erigió nuevas parroquias en todo el Reino de Valencia, adjudicando a los rectores un salario anual de 30 Libras, que deberían obtenerse fundamentalmente de las primicias, mientras que las antiguas tierras de las mezquitas (convertidas casi todas en Iglesias) y sus rentas servirían para la "fabrica" y omamentos de los nuevos templos". De la vieja parroquia del Rafol (núcleo ya casi despoblado), en la zona de la Valldigna, se disgregaron o desmembraron las siguientes: Simat, con su anexo de Xara, las localidades más próximas al monasterio y con mayoritaria población cristiana en esa época; Benifairó, con su anexo de Fulell o Alfulell; Tavernes, con su anexo de Hombria; y Alcudiola, con sus anexos de Masalalí y Favara ${ }^{86}$. Todos esto súltimos núcleos estan poblados por moriscos y dentro de los términos jurisdiccionales del monasterio, salvo Favara. De cual era la realidad de estas nuevas partoquias nos ilustra un proceso que, a instancia del fiscal eclesiástico (y desde luego movido por el nuevo arzobispo, Juan de Ribera), se abrió contra sus rectores a principios de $1570^{87}$.

Fray Jaime Bellvis, monje profeso y a la sazón abad de Valldigna, era el rector del Rafol. Lugar ya totalmente despoblado en esa fecha, existía allí un trapiche donde se fabricaba azúcar durante unos cuarenta días al año y en ese período acudían jornaleros; en la propia Iglesia abundaba el polvo, junto con instrumentos para hacer azúcar y un criado admitió que nunca vío al abad decir misa en aquel recinto, razones por las que el fiscal propuso que se declarase "vaca", pero el convento defendí su mantenimiento por la conveniencia de

84 Hecho contrastado y ampliamente documentado. Sobre las parroquias, en general, ARV, Clero (CL), cajas (c.) 1.902, 1.903-1.904, 1.982 y 1.983-1.984.

85 Para más detalles y referencias documentales y bibliográficas de la reforma parroquial de 1534 y la posterior de 1574, vease nuestro trabajo "Notas sobre la predicación e instrucción religiosa de los moriscos en Valencia a principios del siglo XVI", en Estudis, Revista de Historia Moderna (Universidad de Valencia, 1989), n 15, p. 205-244.

86 Favara, que no pertenece al monasterio, se disgrega de Cullera y se adjunta a Alcudiola. El rector estará obligado a decir una misa en cada jugar los domingos y fiestas. El convento deberá aportar las 30 Libras para sostener al párroco. Como las primicias de Favara solo llegan a 40 sucldos, el rector de Cullera daría al de Alcudiola cada año 8 Libras (ARV, Cl, diversa información en c. 1.902 y $1.903-1.904$, además de Archivo de la Catedral de Valencia, $n^{\circ} 1.626$ ). Según J. SANCHIS SIVERA , la segregación se produjo (se cjecuto) en 1547 (Nomenciator Geográfico-eclesiastico de los pueblos de la Diócesis de Valencia, Valencia, 1922, voz Alcudiola).

87 Son cuatro procesos recogidos en ARV, Cl, c. 2.013-2.014. 
seguir prestando servicio religioso, entre otros a los trabajadores del trapiche. No habiendo podido localizar al abad para examinar su idoneidad como cura párroco, será requerido varias veces por el Patriarca Ribera a la ciudad de Valencia, donde comparece el 7 de marzo, y tras ser examinado por el Procurador Fiscal y un notario y comprobar que era incapaz de "construir" bras del canon, se declaró que "no era habil ni idoneo para poder tener rectoria ni administrar sacramentos".

Identica conclusión se sacó de fray Miguel Pedrós, monje que afirma tener más de setenta años y hace diez que es rector de Tavernes y de su anexo Hombria, habiendole precedido un presbítero secular. La Iglesia se erigí a partir de la antigua mezquita y atiende a una poblaci $\emptyset \mathrm{n}$ de unas $\mathbf{2 0 0}$ casas de moriscos; de su inspección se observa cierto abandono y algunas carencias, mientras que la de la Hombría se encontraba en mal estado (tejados rotos, goteras...); el convento no le da las 30 Libras prescritas por la reforma de 1534 , sino que les otorga las tierras de las antiguas mezquitas para que de sus rentas se sostengan. Fray Miguel Pedrós no sabe igualmente "construir", no tiene muy claro el concepto de sacramento, de los que solo conoce tres (bautismo, extremaución y "unción"); del incesto dirá que era "tener cuenta con alguna monja"; la excomunión "mayor" era "haver herrado contra su perlado y aver hecho alguna eregia" y que la "menor", "quando alguno va por alli y peca mortalmente mirando"; "preguntado si sabe la doctrina christiana dixo que no la sabe sino por un libro"; ideas poco claras tenía también de los "articulos de la fe", algunos de los cuales se le habían olvidado, y de los mandamientos "de la sancta madre yglesia dixo quel primero es amar a dios y que son diez".

La Iglesia de Benifairó, antigua mezquita, estuvo provista primeramente por un clérigo secular, pero el abad nombró párroco el 12 de febrero de 1563 a fray Nofre Pons, el cual no ha obtenido hasta hoy "dispensacion ni abilitacion" para detentar dicha parroquial. Hombre de más de cincuenta años, monje bernardo desde hace 36 , admite que el convento le entrega solo 17 Libras y no las treinta prometidas en la reforma, pero que en cambio "goza" de las tierras que fueron de la mezquita. La Iglesia, que debe atender a una población de 60 casas de moriscos, es un auténtico desastre, tiene parte del techo descubierto y el rector retiraba las imágenes cuando llovía. No lee muy bien ni sabe "construir", y si bien su cultura religiosa no es excepcional, tiene un mayor nivel que el párroco de Tavernes. De su anexo Fulell se dice que tiene la Iglesia descubierta, "las paredes rompidas y abiertas por muchos cabos", sin retablo, ni cruz "ni cosa que pareciese yglesia".

88 "Construir" en el sentido de traducir o escribir en latin.

Sobre economía Eclestástica

Hispania Sacra 49 (1997) 
Fray Juan Talavera, monje profeso de 35 años, es el rector de Simat, aunque antes estuvo regentada por clérigos seculares, y no tiene dispensa. Respecto de las 30 libras de renta "a oydo decir que el convento las avia de pagar al Rector", pero de hecho solo percibe las rentas de las tierras de las mezquitas. Quizá el hecho de que Simat tuviese 70 casas de cristianos y 30 de moriscos podría explicar que la Iglesia estuviese en mejores condiciones: el altar era nuevo, aunque el resto antiguo, no había retablo pero sí figuras de tela y un crucifijo. El propio visitador celebró misa y predicó, advirtiendo que los óleos y la pila bautismal estaban mal provistos. Al religioso "mandole leer en el concilio tridentino y no leyo bien, mandole construir y no supo. Sabe casos de conciencia". La Iglesia de su anexo Xara, que atiende a 38 casas de cristianos viejos, tiene graves deficiencias arquitectónicas ("con muchas señales de lloverse por las paredes...") y la casa que solía ser abadía, en ruinas.

Las conclusiones no pueden ser más deplorables: mal estado de los templos, negligencia en su mantenimiento, el convento no abonaba las 30 libras que debía aportar como perceptor de las primicias, las rentas de las tierras de las Iglesias (antes de las mezquitas) no servían para la fábrica y ornamentos sino para alimentar a los rectores; estos eran monjes nombrados por el abad, sin dispensa ni habilitación suficiente, y no clérigos seculares, su ignorancia religiosa era evidente..., por lo que a juicio del Procurador Fiscal las rectorías "vacan" y sus vicarios perpetuos deben declararse inhábiles. No es difícil imaginar la humillación que tal declaración debió suponer para D. Jaime Bellvis, oriundo de una familia de la pequeña nobleza, abad en su segundo trienio, uno de los hombres más poderosos del monasterio y acusado de pretender convertirse en perpetuo, como la humillación del resto de la comunidad, minusvalorada por su ordinario, quien pretendía con ello arrebatarles algunos de los cargos más atractivos que podían alcanzar. El recien llegado arzobispo Juan de Ribera (1569) poco menos que les había declarado la guerra, como veremos tambien en otros temas. Pero estos intentos reformistas, consecuencia de los nuevos aires que aportó el Cocilio de Trento, estaban en gran parte destinados a fracasar ante la solidez de los privilegios de origen medieval que el monasterio iba a hacer valer ante las autoridades competentes.

En la visita pastoral de 1576 y 1579 a Simat y a Benifair $6^{89}$, ahora con carácter ordinario, siguen los frailes detentando las rectorías ${ }^{90}$. La situación de las Iglesias parece mejor, pero de todas formas se observan grandes diferencias

${ }^{89}$ Visita pastoral de Simat y Xara en 1576 y 1579 , y Visita pastoral de Benifairó y Alfulell en 1579 (ARV, Cl, c. 2.061).

${ }^{90}$ En 1576 es rector de Simat el mismo que en 1570, fray Joan Talavera, pero en 1579 (por nombramiento desde el 17 de agosto de 1577) lo es fray Jose Garrigues. En Benifairó es rector en 1579 el monje fray Joan Borro, con nombramiento desde el 3 de junio de 1573.

Sobre economía Eclesiastica Hispania Sacra 49 (1997) 
entre la de Simat $^{91}$ y Benifairó ${ }^{92}$, y se dirigen especiales mandatos a la población morisca: el rector estará obligado so pena de 10 Libras a observar los sínodos y constituciones dictadas para los nuevamente convertidos, especialmente acerca de "matar la carne, desposorios y saber la doctrina, como de enterramientos y otras cosas..."; deberá explicar las constituciones, además de llevar un "capatron" de todos los feligreses y cada día de fiesta o domingo pasar lista en el ofertorio; que procure que los enfermos le llamen para "ayudarles a bien morir": que el alguazil de moriscos haga bien su oficio, "no disimulando con ellos antes los execute las penas",etc.

La complejidad del tema de las parroquias viene dada por la variedad de aspectos que confluyen en ellas, que se convierten en procesos paralelos,y de los que daremos una sucinta noticia atendiendo a: 1) los diezmos que debía abonar Valldigna; 2) la titularidad de las tierras de las antiguas mezquitas; y 3) el carácter vitalicio de las rectorías.

1) Está fuera de toda duda que las tierras de la Valldigna sujetas al monasterio estaban exentas de pagar diezmos y primicias de la producción agrícola, en virtud de especial privilegio concedido al mismo, que en cambio debía abonar una cierta cantidad a la autoridad eclesiástica territorial. Esto se repite y prueba sistemáticamente, si bien se desconoce la fecha del documento o privilegio originario, aunque desde los orígenes de la fundación se alude ya a esta situación como un favor especial del obispo y cabildo de la ciudad de Valencia al monasterio a fin de facilitar su consolidación, cifrandose en 1.300 sueldos (65 libras) la contraprestación económica. En la carta de población de 1366 se advierte que en las particiones que deben pagar los vasallos se incluyen los diezmos. No contradice esta situación la Sentencia Arbitral de 1457 y la de 1532, desautorizando ésta al convento que pretendía que pagaran los vasallos las 60 libras (sic) que abonaba en concepto de diezmos. Por este motivo estaba

91 En la sacristía de Simat se contabilizan 33 piezas de plata y hornamentos , y 17 en Xara, cuando solo son 11 eл Benifairo y sin mención para Fulell. En Simat se convocó a los feligreses de las đos Iglesias en una misa mayor que se celebró en el monasterio; se lleva libro de bautizados y matrimonios.En ambas Iglesias hay pila bautismal, camparario y campana, bancos, púlpito de madera, pero no altar reservado al santisimo Sacramento. Disponen las dos de varios "bacines y de mandas", que reciben limosmas en "pan" y dinero, las cuales administran diversos feligreses. La mayoría de los mandatos atienden a la administración de los bacines y a que se compre un misal moderno para $X$ ara a fin de que se diga misa en dicha Iglesia. En la visita de 1579 se ordena construir en la lglesias un "yaso para enterrarse" y cerrar el "fosar", donde de ordinario se entierran.

92 Si bien el altar "se alja bien aderesado", se ordena a los jurados que deben ensanchar y alargar la Iglesia a fin de ser suficiente para atender a los fieles, que se haga un retablo y pila para bautizar, unas crismeras y un vaso para "olio", una patena, casullas, camisas..., además de una campana y bancos para sentarse; que se construya una abadía para que en ella pueda habitar el rector, además de dos cruces grandes de argamasa en los caminos.

Sobre economía Eclesiástica Hispania Sacra 49 (1997) 
obligado el monasterio a abonar las 30 libras de salario de los rectores de las nuevas parroquias en la reforma de $1534-1535^{93}$.

Pero una cantidad fija en dinero se desvalorizaba con el transcurso del tiempo. En 1566 comenzó un larguísimo pleito ${ }^{94}$ entre el arzobispado de Valencia y el monasterio, que no acabará hasta principios del siglo XVII, al pretender el primero que debía actualizarse la cantidad o introducirse una detracción decimal como en otros lugares, mientras que el segundo sostenía que tenía elevadísimos gastos para atender a la comunidad y que debían respetarse los privilegios medievales. Entre otros documentos se reproducen actas de los pagos efectuados por el convento. Así, en 1422:

- Al arzobispo de Valencia por el diezmo del valle, "part bisbal"

818 s. 10 d.

- A los pabordes de Valencia, por su parte anual

$450 \mathrm{~s}$.

- Al artiacha de Xativa, por su parte anual

80 s. 2 d.

- Al notario, por las apocas

$3 \mathrm{~s}$.

Es decir, 1.352 sueldos o, si se quiere, 67 Libras y 9 sueldos más los gastos del notario. Por esos años, y en el mismo proceso, se aportan cifras (cuyo análisis crítico no efectuamos ahora, pero que no son fantásticas), según las cuales se valoraba en 14.000 o 15.000 Libras, otros en 20.000 , la producción agrícola del valle; algún testigo consideraba que el diezmo de la Valldigna valdría unos mil ducados anualmente ${ }^{95}$. No cabe duda, pues, que la situación era muy favorable al convento.

En la carta-puebla de 12 de diciembre de 1609 , otorgada con ocasión de la expulsión de los moriscos, se dirá que "por quanto los dichos vecinos y pobladores no habian de tener ni tenian obligacion de pagar de los frutos que cogerian en las dichas tierras de huerta secanos y marjal, Derecho de Diezmo ni otro alguno, mas de lo que se habian dicho y especificado arriba (o en los capitulos antecedentes) por quanto de tiempo inmemorial y en virtud de legitimos titulos y por antigua composicion el referido Abad y Convento por todos los demas que se podian deber y deberian de todos los frutos que se cogian en dicha valle, habia acostumbrado a dar y pagar, y efectivamente habia dado y

${ }^{33}$ Referencias documentales que se recogen en un largo "Memorial Ajustado" (impreso en Valencia, 1799) a raíz de un pleito entre el monasterio y Tavemes a fines del siglo XVIII (ARV, Cl, c. 2.082-2.083), y cuyos originales o copias manuscritas se conservan en otras cajas.

94 ARV,Cl, libro 1.696. Tambien en c. 1.919-bis y 1.920. Pocos años antes, en 1555, había comenzado otro pleito sobre el pago de los diezmos de la importante granja de Benivayre, en el término de Carcaixent (Ibidem, Real Audiencia, $2^{\circ}, S, n^{\circ} 86$ ).

95 Ibidem, libro 1.696, fol.370 y $381 \mathrm{v}^{\circ}$, por ejemplo. 
pagado y debia anualmente en satisfacer al Arzobispo y Canonigos de la Seo de esta ciudad y Arcedianato de la de Xativa 67 libras 9 sueldos 9 dineros" hecho nuevo - la repoblación- y que no debían establecerse tierras sin la obligación de deducir el diezmo, y el convento volverá a recordar con éxito sus títulos legítimos e inmemorial posesión ${ }^{97}$.

Un aspecto colateral de los diezmos es el relativo al derecho del escusado, concedido por Pio $\mathrm{V}$ al rey Felipe II por Bula de 11 de mayo de 1571, y consistente en la donación a la autoridad real del prođucto de la casa mayor diezmera de cada lugar o zona. El peculiar régimen de la Valldigna planteó problemas: los vasallos no pagaban diezmos, por lo que en principio podían resistirse a abonarlo, y en el supuesto de pagarlo quedaba por determinar cual era la casa mayor diezmera, pues no había constancia contable de la detracción decimal; aquel que fuese nombrado a tal efecto se sentía agraviado porque se veía gravado individualmente con un nuevo y considerable impuesto (la décima parte de su producción agrícola);el convento solo venía obligado a entregar una determinada cantidad al arzobispado, pendiente a su vez de decisión judicial, y no estaba dispuesto a aumentar considerablemente esa prestación ni a ser nombrado el propio monasterio casa mayor diezmera del valle ${ }^{98}$. Tras diversos escarceos procesales, el doctor en ambos derechos micer Vicente Jorda resolvió una reclamación de Juan Royz y otros, perjudicados por haber sido nombrados sujetos a dicha exacción, en el sentido de que fuese cual fuese la casa elegida para tributar el escusado, posteriormente se repartiese su importe entre todos los vecinos y habitantes del valle "por via de tacha y derrama". Una asamblea general de vecinos efectuada el 18 de agosto de 1585 optó mayoritariamente por esta solución", pero no faltaron descontentos que la impugnaron ni problemas para su aplicación ${ }^{100}$.

\footnotetext{
96 Capítulo $18^{\circ}$ de la carta puebla, publicada en GASCON PELBGRI,V., op. cit., p. 167.

$\because$ Documento de 14 de febrero de 1610 por el que el arzobispado deniega la pelición de hacer nuevas poblaciones sin exigir diezmos, amenzando con incurrir en pecado mortal a los repobladores; y réplica de padre fray Pablo Perez Amal, síndico del convento, el 1 de marzo de 1610 (ARV, Cl, c. 1.920).

98 Eso pretendieron los administradores del escusado en atención a las tierras que gestionaba directamente el convento y las abundantes cosechas que recogia (vid. información sobre este pleito, sustanciado a fines del siglo XVI, en ARV, Cl, caja 1.926+1.927).

99 Documentación variada sobre el escusado en ARV, Cl,c. 1.971, 1.972-1.973 y 1.920, además de algunas referencias en el "Mernorial Ajustado" (c. 2.082-83).

100 Se concentraron 221 vecinos y de ellos votaron dicha solución 151; 79 que la pagase exclusivamente la casa nombrada y 47 "quien debia pagarlo". La Foya Alta impugnó este acuerdo, pero Benifairo y Fulell, dos de los pueblos de la misma, desistieron en 1586. Aquellas casas nombradas se encontraron a veces con la resistencia o la morosidad para que la totalidad de los vecinos les resarciese de lo que habían abonado a los administradores del escusado, con quienes tambien pleitearon por

Sobre economía Eclesiástica

Hispania Sacra 49 (1997)
} 
En ese sentido, en la citada carta de población de 12 de diciembre de 1609 (capítulo 18), tras la indicación sobre la exención de pago de diezmo ya reproducida, se advierte:"lo que no se entendia ni debia entenderse en quanto al Derecho del Excusado, y facultad que su Magestad tenia de nombrar una casa mayor diezmera por razon de la pila de dicha Valle, por quanto la casa que seria nombrada habia de pagar el debido y justo Diezmo de todos los frutos que cogerian a mas de la parte que habia de dar a la dicha Señoria conforme lo que anteriormente se habia convenido; y no siendo justo que aquella carga y obligacion la sostuviese uno de dichos pobladores, sino que se repartiese igualmente entre todos los del Valle; por ello se debia ver la cantidad de frutos que hubiese dado la tal casa diezmera nombrada por su Magestad, y que los tales frutos se estimasen e hiciese entre todos los Vecinos y habitadores de la Valle, pagando cada uno su parte, de suerte que todos participasen de dicho cargo y obligacion, y prestacion de dicho Diezmo conforme a lo que cada vasalo cogiese, participando por su parte la casa que seria nombrada diezmera"101.

2) A raíz de la unidad religiosa que los nuevos tiempos imponían, de la conversión forzosa de los mudéjares en cristianos y de la transformación de las mezquitas en Iglesias, las tierras que aquellas tenían (resultado de la donación de los particulares) fueron adjudicadas y amortizadas a los nuevos templos cristianos, obteniendose la franquicia del derecho de amortizacion. La reforma parroquial de 1534-1535 destinó, con carácter general, las rentas que se obtuviesen de su explotación a la "fabrica" de las Iglesias. Además, se declaró oficialmente que provisionalmente podrían vivir de ellas también los alfaquíes, quienes se habian quedado sin trabajo ni ocupación con la desaparición del Islam, aunque no tenemos constancia de la efectividad de tal propósito ${ }^{102}$.

Un inventario general bastante completo de 1569 cifraba estas tierras en la Valldigna en unos 212 campos repartidos entre los distintos lugares, que quizá no debían superar en mucho las 212 hanegadas, pues es manifiesta la pequeñez del tamaño de las parcelas cuando se precisa. La gran mayoría eran tierras de huerta: 157 campos de "orta" (74'0\%); 9 de huerta con arboles (4'2\%); 7 de

diferencias económicas (ARV, Clero, cajas 1.971 y 1.972-1.973). En 1600, en un momento crítico de las relaciones entre vasallos y convento, aquellos se resistieron en via procesal a pagar el escusado argumentando que en la carta puebla de 1366 se especificaba con claridad que los diezmos estaban incluidos en las particiones de cosechas (Ibidem, c. 1.920).

101 En 1623 el administrador del escusado quiso nombrar al convento casa mayor diezmera, pero fué desautorizado por los tribunales (ARV, Cl, c. 1.971).

$102 \mathrm{La}$ información sobre los avatares de las tierras de las antiguas mezquitas se encuentra ante todo en ARV, Cl, caja 2.023-2.024; 1.996-1.997 (con un resumen general sin fecha titulado "Sucinta noticia de las tierras de las mezquitas y de los expedientes q. ha tenido el monasterio sobre su aplicacion a las Iglesias de esta valle"); caja 1.993-1.994; 2.036-2.037 y 2.135-2.136, principaimente. 
secano (3'3\%) y 39 de árboles (olivos, algarrobos y moreras) sin especificar $\left(18^{1} 3 \%\right)^{103}$. Un documento del convento de finales del siglo XVI las valoraba en su conjunto en 3.500 ducados, cifra que hay que enjuiciar como aproximada y no alejada de la realidad ${ }^{104}$. Se explotaban habitualmente cediendolas en arrendamiento a diversos particulares, pero resulta muy problemático evaluar su rentabilidad ${ }^{105}$. Se puede precisar más la fiscalidad señorial a la que estaban sujetas: censos en dinero fijos, de origen bajomedieval, llamados "magram", y que ascendían a unas 143 libras y 19 sueldos $^{106}$.

Tal como hemos afirmado, estas rentas debían sufragar la construcción, reparación y mantenimiento de los templos ("la fabrica"), los ornamentos y demás gastos, pero en Valldigna la situación estaba totalmente alterada. Dado que el monasterio se abstenía de abonar las 30 Libras de salario a los rectores, en su defecto les entregaba las tierras de las mezquitas para que con sus rendimientos se mantuviesen los monjes que tenían adjudicadas las parroquias. Frente a ello reaccionó el arzóbispo Ribera reclamando que con estos ingresos se procediese a la reparación de la Iglesia de Fulell, anexo de Benifairó, que se encontraba en deplorable estado,y a lo que se opuso el convento ${ }^{\mathrm{I07}}$. Tambien los vasallos protestaron porque las rentas de estas propiedades debían servir para la "fabrica" de las Iglesias, pero las tenía usurpadas el convento; el abad y vicarios les exigían pagar la mitad de los gastos del mantenimeinto de las Iglesias y ornamentos, cuando propiamente no debían pagar nada ${ }^{108}$.

103 ARV, Cl, c. 2.036-2.037, "ferma de dret " del convento contra el arzobispado de Valencia, 1569. Existen otros inventarios de menor fiabilidad e incompletos en caja 2.023-2.024, por pueblos del valle que dan resultados globales próximos a los descritos: Simat, 26 campos; Xara, 38; Benifair6,14; Fulell, 6 o 7 "bancals";Tavernes, 68; Hombría, 31, además de cerca de treinta trozos con árboles (olivos, algarrobos y moreras). Son campos normalmente de una hanegada (o tahulla) o fracción de ella, rara vez mayor, y en muchos casos no se especifica la extension.

104 Documento sin fecha dirigido a Felipe II (ARV, Cl, c. 2.023-2.024). Valoración total que no parece descabellada, pues la mayoria de campos son de huerta y hacia 1600 una hanegada de huerta podía valer en la Valldigna más de 20 Libras.

ios Así , un documento sin fecha dice que en Taverna hay 65 campos arrendados en 25 Libras al afio, pero que podrian arrendarse por el doble ; en Hombría se citan 31 trozos de tierra arrendados en 1604, cuyo importe de alquiler ascendía a 58 Libras y 12 sueldos (ARV, Cl, c. 2.023-2.024). Unas declaraciones testificales en los pleitos con el convento en 1593-1594 afirman que las tierras de las la Iglesia de Tavernes supone anualmente 200 libras, cantidad que parece claramente exagerada (Ibidem, c, 2.212-2.213).

106 Cálculos efectuados cuando se intenta precisar a principios del siglo XVII el total de censos en dinero que debian tributar a la sefioria (ARV, Cl, c. 2.135-2.136, carta de 24 de septiembre de 1617).

107 ARV, Cl, c. 2.023-2.024, proceso iniciado el 29 de octubre de 1569).

108 Declaraciones testificales en los pleitos con el convento, años 1593-1594 (ARV, Cl, c. 2,2122.213). Algunas declaraciones afirman que el convento se comprometió a pagar la mitad de los gastos de la "fabrica".

Sobre economia Eclesiástic Hispania Sacra 49 (1997) 
Pero el gran problema que plantearon estas tierras fué el de su titulariad. En la Valldigna, como en otras zonas del Reino de Valencia ${ }^{109}$, los señores territoriales se consideraron propietarios absolutos de ellas y tendieron a usurparlas como un bien particular, entendiendo que se había consolidado el dominjo directo con el dominio útil de unos bienes sujetos a enfiteusis. Un resumen relativo al convento dira: "segun fueros del Reyno de Valencia las tierras, tanto de los moros que las dexavan extrañandose como las de las mezquitas extinguidas devian pasar a los dueños territoriales, no solo en cuanto al dominio directo, el que siempre retuvieron, si no que tambien en quanto al util; y como muchos de los moros de esta valle havian desertado de muchos años antes, como los de Xara, y las mezquitas estavan extinguidas y abolidas por ordenes y disposiciones del Sr. Emperador D. Carlos V, en que mando las mezquitas se abolieran, y que los moros se convirtieran o salieran de sus dominios y reynos, por tanto, tanto las tierras de las mezquitas como las de los moros que havian pasado a otras partes devian quedar del Monasterio como señor territorial solidandose el dominio util con el directo" 110 . La interpretación del convento homologaba el caso de las tierras enfitéticas, cuyo dominio util se había consolidado con el directo por la huída de los vasallos y abandono de sus bienes, con el tema de las antiguas mezquitas, convertidas ahora en parroquias.

Esta situación e interpretación entró en crisis en el último tercio del siglo XVI, cuando por el arzobispado de Valencia, y siempre contando con la circunstancia personal de que estaba regido por $D$. Juan de Ribera, como administrador general de las rentas de dichas Iglesias, impugnó tal interpretación y las consecuencias que de ella se podían deducir. Solo a principios del siglo XVII pueden considerarse cerradas las diversas instancias, recursos y apelaciones a que dió lugar, estableciendose finalmente que el convento tenía y mantenía el dominio directo, pero que el dominio útil de tales tierras había pasado a las parroquias y a sus titulares, los rectores. Estos podrían administrarlas y disfrutar sus rentas, aunque con la obligación de pagar al señor territorial y directo, es decir, al convento, los correspondientes derechos señoriales ${ }^{111}$.

Ello supuso a continuación otros procesos para precisar ahora cuales eran con exactitud esos derechos y efectuar las correspondientes liquidaciones y

\footnotetext{
109 Ciscar, E., "Notas sobre...", p. 214, nota 43.

110 Fragmento del documento "Sucinta noticia de las tierras de las mezquitas..."(ARV, CL, c. 1.996.97).

111 Documento citado en la nota anterior; documentación sobre sentencias de 1598 a 1601, en ARV, Clero, c. 2.023-2.024; Crida de 21 de julio de 1598, publicada por orden de su Magestad, dando a conocer la decisión tomada sobre el tema de las tierras de las antiguas mezquilas del valle de Valldigna (Ibidem, c. 1.993-1.994).
} 
compensaciones ${ }^{112}$. Pasados los años los visitadores de las parroquias pusieron de relieve que "los administadores de las tierras de las mezquitas no davan cabal cuenta y que quedavan alcanzados en grandes cantidades, por motivo que acostumbrando a dar dhas tierras en arriendo, no podían cobrar de los arrendadores los tanto estipulados; y que aun les era imposible por motivo de su grande pobreza". Como esta situación era perjudicial para las Iglesias, en 1654 el arzobispo de Valencia D. Pedro Urbina y el abad D. Rafael Trobado llegaron a un acuerdo, mediante el cual el primero renunciaba a esas tierras a favor del monasterio, y éste se obligaba a pagar con carácter permanente unas cantidades anuales a las Iglesias: 35 Libras a la de Simat, 25 a la de Benifairó y 50 a la de Tavemes ${ }^{13}$.

La solución de este problema contribuyó a mejorar sensiblemente la situación económica de las parroquias. Estas cantidades quedaron integradas en otras superiores que con el nombre de "congruas" pagaba el convento cada año a los rectores, cifrandose en $470 \mathrm{~L}$. anuales para las cuatro parroquias de Simat, Benifairo, Tabernes y Alcudiola, más otras $60 \mathrm{~L}$. que se computaban por el gasto de celebrar misa todos los domingos y festivos en la granja de Barx ${ }^{114}$. A ello había que sumar "el pie de altar", calculado aproximadamente en un ducado por vecino ${ }^{115}$. Es fácil comprender, pues, que los monjes agraciados con una "rectoria" se resistiesen a renunciar a ellas o a perder el carácter vitalicio de su posesión o titularidad: ello les permitía vivir independientes del ré-

112 Sentencia de 12 de diciembre de 1617 por la que se establece que la Iglesia de Taverna y Hombria debía pagar cada ańo al covento 47 Libras, 18 sueldos y 9 dineros del derecho de "magram" y demás censos con luísmo y fadiga, pero que se debía compensar esta cantidad con la que el convento estaba obligado a dar al rector.En 15 de diciembre de 1620 se admitio, a favor del convento, que los jurados de los pueblos del valle le reconociesen como señor directo de las tierras de las mezquitas, le pagasen los censos debidos (143 Libras, 19 sueldos de "magram") y aceptasen cabrevarlas (ARV, Clero, c. 2.023-2.024).

113 ARV, Cl, c. 1.996-97 ("Sucinta noticia..."). Hay alguna alusión a que durante el siglo XVIII los párrocos quisieron reclamar la posesión y usufructo directo de esas tierras, pero no hemos encontrado constancia documental evidente. Pero si esta probado que a fines del siglo XVII y a principios del XIX los párocos, y en particular el de Tavemes, reclamaron al convento aumento de las "congruas".

114 ARV, Cl, c. 2.075-2.076, relación de ingresos y gastos hacia 1680 . Hay constancia de recibos de los parrocos por cantidades pagadas por el convento en concepto de "pensión" que reciben anualmente (Ibidem, c.2.022).

lis Este es el cálculo que hace el visitador fr. T. Gómez en 1666 (AHN, Consejos, leg. 49.904, fol. 37 y ss.). Segón su version, cada una de las cuatro parroguias recibía 100 ducados de congrua, sin hacer alusión alguna a la renta de las tierras de las antiguas mezquitas; a la granja de Barx, con solo 12 feligreses o vecinos, acudía totos los domingos y festivos un monje del monasterio sin recibir congrua por ello. Subsistia la "retoria" del Rafol con un solo feligres, y alli solo se decía una misa al año; las rentas de sus propiedades era de 50 o $150 \mathrm{~L}$. al affo(incierto en el original); en esa epoca su titular era D.R. Trobado. Quiso introducir reformas (distribución de congruas, lugar donde deben residir los párrocos...), pero no tuvieron continuidad.

Sobre economía Eclesiástica

Hispania Secra 49 (1997) 
gimen claustral del convento, de forma más libre y autónoma, con unas rentas propias frente al voto de pobreza benedictino.

3) Si las nuevas parroquias creadas en la Valldigna se ocuparon por clérigos seculares a raíz de la reforma de 1534-35, tal como afirman los monjes investigados en los procesos a instancias del Procurador Fiscal en 1570, ya comentados, es evidente que desde mediados del siglo XVI fueron provistas de igual manera que lo había sido la parroquia del Rafol durante la Baja Edad Media en ejercicio del derecho de patronato: el abad propone al obispo un fraile como rector, que normalmente lo aprueba. Tal nombramiento tenía carácter vitalicio o perpetuo, y solo podía quedar vacante por defunción o por renuncia del titular.

Por tanto, en el siglo XVI y XVII vemos que los rectores de las parroquias son monjes del convento, incluso con frecuencia religiosos destacados a los que se otorgaba indefinidamente uno de los cargos más atractivos a los que podía acceder un monje. De hecho, muchos de ellos fueron elegidos abad por la comunidad. Así, durante el siglo XVI, D. Juan Bonanz, vicario del Rafol; D. José Garrigues (Simat);D. Jaime Bellvis (Rafol) ;D. Francisco Gil (Rafol). Durante el siglo XVII: D. Juan Costeja (Benifairó); D. Francisco Caldero (Simat); D. Jeronimo Talens (Alcudiola); D. Nicolas Talavera (Benifairo y Simat); D. Francisco García (Tavernes); D. Francisco Cruañes (Tavernes); D. Pedro Tudo (Benifairo); D. Jaime de la Tonda ((Tavernes); D. Francisco Garí (Simat); y D. Vicente Lloret (Benifairo) ${ }^{116}$.

Si el Rafol era un lugar ya deshabitado, no así los restantes núcleos. En ellos había una población que atender pastoralmente (predominantemente morisca hasta 1609, cristiana después), y los religiosos nombrados vicarios perpetuos podían, si no debían, vivir junto con sus pueblos, en sus respectivas casas abadía, servidos por criados y con ingresos propios, independientes de la vida monacal que habían profesado. Acostumbrados a esta vida más cómoda, se les hacía muy cuesta arriba reintegrarse a la vida monástica. Entre las críticas que se efectuaron a la situación relajada del monasterio a fines del siglo XVI se dirá de los curatos de los pueblos que se los reparten los religiosos, "que viven en ellos con mucha libertad y con patrimonio propio y atienden a grangerias de hazienda para si y recogen a los discolos y dan mal ejemplo a los del convento y quando han de volver a el dexando el regalo y libertad de que gozavan en los curatos con difficultad se aplican a seguir el coro ni la observancia y rigor de la Religion", además de que no son "graduados en letras"117.

116 Vid. referencia bibliografica de la nota 12 sobre relaciones biograficas de los abades.

${ }^{117}$ AHN, Consejos, libro 2.397 , fol. $249-250$, año 1595 , resumen de parte de la información resultan de de la visita del Obispo de Utica. 
La intención de reformar este estado de cosas impulsó al Concilio de Trento y al papa Pio V a establecer que "en las parroquiales unidas a los monasterios, se destinasen monges para vicarios, no perpetuos, si amovibles al arbitrio de su Superior, con tal que con el vicario huviessen de habitar a lo menos quatro monges". Más tarde, en 1592, el papa Clemente VIII ratificó esta norma ${ }^{118}$. La clave de la novedad consistía en que las rectorías no serían perpetuas, sino "amovibles", por lo que tras desempeñar un determinado destino de cura de almas, el monje regresaría a su originaria actividad y misión monacal. Pero la Valldigna no se dió por enterada. No obstante, a veces se trasluce una cierta mala conciencia por esta función parroquial que de hecho se contradecía con el espíritu de vida claustral y comunitaria que implicaba tomar los hábitos del Císter ${ }^{119}$.

No puede sorprender, pues, los roces con el arzobispo Ribera por las provisiones de los curatos y que los procesos se hiciesen frecuentes desde el último tercio del siglo XVI. Además, en la reforma parroquial que éste implantó en 1574 (reestructuración de términos, erección de nuevos curatos, aumento del salario de los párrocos a 100 libras...), se había separado la localidad de Hombria de Tavernes y se la había unido al despoblado Rafol, pero esto no fué bien visto por el convento, quien bloqueó la situación no presentando monje para tal destino ${ }^{120}$.

En el Capítulo General de la Congregación del Císter de Aragón del año 1623 se estableció como "definición", que a medida que fueran vacando las Iglesias, se rigiesen en adelante por vicarios amovibles "ad nutum Abbatis", to que fué aprobado por el papa Gregorio XV en su Bula de 21 de febrero de $1623^{121}$. Pero la Valldigna siguió ignorando el tema.

Una intervención personal de Felipe IV, mediante una carta dada en Madrid el 25 de noviembre de 1664, instó para que se diese cumplimiento a la citada

\footnotetext{
118 Esta información es muy repetida en la documentación relativa a las parroquias, si bien las palabras textuales se han tomado de un impreso firmado por cl abad D. fray Bruno de Salcedo (siglo XVIII), que se conserva en ARV, Clero, c. 1.902.

119 En una carta al Rey de 2 de diciembre de 1616 , el abad relata la pobreza del monasterio y las necesidades de los monjes, razón por la cual "muchos de ellos sirven curatos de seglares, empleo contra nuestra profesión monástica, solo por no haver para ellos sustento" (Documento publicado y comentado por A. MASOLIVER, op. cit., p. 322-323).

120 Fueron frecuentes los pleitos sobre la provisión de la parroquia del Rafoltasí, fray Francisco Gil presentará una "firma iuris" sobre su posesión como rector del Rafol en 27 de febrero de 1592; a su fallecimiento en 1614, nuevamente se plantea el problema. Tambien tuvo dificultades el nombramiento en 1577 de fray Jose Garigues como rector de Simat y Xara (ARV,Cl, c. 1.982 y 1.983-1.984).

121 Impreso de fr. Bruno de Salcedo (ARV.Cl, c. 1.902) y otros documentos en Ibidem, c. 1.902 y 1.903-1.904. También en MASOLIVER, A., op. cit., p. 113, como súplica de la Congregación al Pontífice en 1622.
}

Sobre economía Eclesiástica Hispania Sacra 49 (1997) 
definición ${ }^{122}$. En otra de 8 de febrero de 1665 al virrey de Valencia se insiste en la cuestión, ordenándose se ejecute la Bula de Gregorio XV, además de que se suprima la vicaría vacante del Rafol. En cartas de 28 de noviembre de 1668 al arzobispo y de 16 de marzo de 1670 al virrey, la reina gobernadora $\mathrm{D}^{\mathrm{a}} \mathrm{Ma}$ riana de Austria vuelve a insistir, poniendo de relieve los "reparos" que ha presentado el monasterio ${ }^{123}$. Pero nada se consiguio, ni siquiera la supresión de la vicaria del Rafol ${ }^{124}$.

En 1686, y tras un proceso con la Jurisdicción Eclesiástica cuatro años antes ${ }^{125}$, el conflicto adquiere actualidad. Ya sea a instancias reales o del arzobispado de Valencia, el statu quo de los curatos del valle se siente amenazado. El 12 de enero de 1686 el convento de Valldigna presenta una "firma iuris" en defensa del derecho de patronato, alegando estar en pacífica e inmemorial posesión del derecho de proponer religiosos como curas para el Rafol, Tabernes, Simat y Benifairo, que posteriormente, aprueba el ordinario, arzobispo de Valencia, lo que confirman distintos testigos ${ }^{126}$. Meses más tarde, el 14 de diciembre de 1686, el padre Pedro Tudo, rector de Benifairo desde el 31 de marzo de 1659; fray Ramon Sans, rector de Simat desde el 23 de noviembre de 1676; el padre fray Vicent Mas, rector de Tavernes desde el 22 de abril de 1679;el padre fray Joseph Portell, rector de Alcudiola desde el 6 de enero de 1677; y el padre Silvestre Castany,rector del Rafol desde el 10 de marzo de 1670, interponen otra firma de derecho en semejantes términos, insistiendo ahora en el carácter perpetuo de las vicarías y de su indiscutible "posesión" desde las fechas indicadas ${ }^{127}$.

A pesar de estas demandas, diversos documentos posteriores refieren que el convento "tuvo resuelto" el problema desde el 5 de enero de 1687, decidiendose a asumir la definición del carácter temporal de las vicarías, aunque se resis-

\footnotetext{
12 Alusión a la carta en el impreso citado del abad D. Bruno de Salcedo, ARV,Cl, c. 1.902.

${ }^{123}$ Estas cartas se recogen en AHN, Consejos, tibro 2.434, fol. $24-25$ y 167-168, salvo la de 8 de febrero de 1665 que es simplemente aludida en la última referencia documental. En la de 28 de noviembre de 1668 la Reina (o el Consejo de Aragón) plantea la supresión de la rectoria del Rafol a raíz de la muerte de su último titular D. Rafael Trobado, fallecido en el mes anterior (octubre de 1668).

${ }^{24}$ La vicaria del Rafol susbsitia en 1686 , como veremos a continuación en la firma de derecho de los párocos en esa fecha. D. Gerardo Castillo,vicario perpetuo de Rafol de Valldigna, arrendaba en 1745 todas las tierras de dicha vicaría por 85 libras cada af́o (ARV, Cl, c. 1.940-1.941).

125 Pleito entre la Jurisdicción Real y el monasterio de Valldigna contra la Jurisdcción Eclesiastica en 1682, porque ésta no deja ejercer sus funciones y derechos (derecho de patronato y reserva de curatos para los monjes) al convento, con la consiguiente "ferma de dret" de éste en defensa de su inmernorial posesión (ARV,Cl, c. 1.903-1.904).

${ }^{126}$ El proceso se encuentra en ARV, Cl, c. 2.210-2.211. Sobre el concepto de Firma de Derecho o "finna iuris", vid. nuestro trabajo, "La ferma de dret en el derecho foral valenciano", en Anuario de Historia del Derecho Español, Madrid, 1992, p. 327-354.

127 ARV, Cl, c. 1.982 y sobre todo $1.983-84$.
} 
tieron "los señores ordinarios". Es decir, habrá que entender que se aceptó finalmente pero no se pudo aplicar de inmediato, sino solo a medida que iban cesando los párrocos. Pero cuando en 1728-1729 quedó vacante la parroquial de Tavemes y se nombro a fray Francisco Crespo como vicario temporal, otro fraile valldignense, fray Vicente Soler (quizá posible aspirante a esa plaza..., o por considerar que los monjes no debian renunciar a ese derecho) se opuso planteando un arduo, complejo, rebuscado y costoso pleito... ${ }^{128}$.

En los años treinta del siglo XVIII, el abad fray Bruno de Salcedo Enríquez de Navarra atribuirá al "demonio" la responsabilidad del tremendo retraso en la aplicación de las constituciones originarias del Concilio de Trento y los problemas y presiones posteriores, incluídas las más próximas del pleito interpuesto por fray Vicente Soler :"Pero como el enemigo común procura con tanta vigilancia entre el buen trigo sobresembrar zizaña, no puede el Monasterio suplicante atribuir a otro los embarazos, que por muy cerca de dos siglos han detenido la execución de tan santas y saludables Constituciones Apostólicas, respecto solo de las vicarias dependientes del Monasterio de Valdigna, hallandose ya observadas en todos los demás de estos Reynos de España..."129.

12s Información muy reiterada, vg. en ARV, Cl, c. 1.902 y 1.903-1.904: Las diversas instancias del pleito acabaron dando la razón a $V$. Soler, pero este renunció finalmente a sus derechos y los pátrocos se convirtieron en "amovibles" (GASCON PeLEGRI, V., op. cit., p. 211-213). Solo en 1732 se registra pormenorizadamente un gasto en este pleito de 5.042 libras, 10 sueldos.

129 Impreso conservado en ARV, CI, c. 1.902, sin fecha, pero encabezado por el citado abad, que tuvo tal dignidad en los periodos $1728-1732$ y $1736-1740$.

Sobre economía Eclesíastice

Hispania Sacra 49 (1997) 